\title{
Predicting forest cover changes in future climate using hydrological and thermal indices in South Korea
}

\author{
Sungho Choi ${ }^{1}$, Woo-Kyun Lee ${ }^{1, *}$, Doo-Ahn Kwak ${ }^{1}$, Sangchul Lee ${ }^{1}$, Yowhan Son ${ }^{1}$, \\ Jong-Hwan Lim ${ }^{2}$, Joachim Saborowski ${ }^{3}$ \\ ${ }^{1}$ Division of Environmental Science and Ecological Engineering, Korea University, 136-701 Seoul, South Korea \\ ${ }^{2}$ Korea Forest Research Institute, 130-712 Seoul, South Korea \\ ${ }^{3}$ Institute of Forest Biometry and Informatics, Georg-August-University Göttingen, 37077 Göttingen, Germany
}

\begin{abstract}
We studied the potential responses of forest vegetation to climate change in South Korea using a Korea-specific forest cover distribution model based on hydrological and thermal indices. The past and future climatic parameters were converted to hydrological and thermal indices that have been reported as climatic controllers of forest vegetation distribution: (1) the Precipitation Effectiveness Index (PEI), (2) Warmth Index (WI), and (3) Minimum Temperature of the Coldest Month Index (MTCI). The vegetation map from the Ministry of Environment was applied to determine the optimal habitat PEI, WI, and MTCI ranges for major tree species in Korea. Then, 8 plant functional types (PFTs) were defined according to the analogies in the optimal habitat PEI, WI, and MTCI ranges, and the result was named the Hydrological and Thermal Analogy Groups (HyTAGs). The HyTAG model was used to simulate the potential forest cover distribution of Korea in the past (1971 to 2000), near future (2045 to 2065), and far future (2080 to 2099) with 3 IPCC climate change scenarios (B1, A1B, and A2). The potential forest cover distribution changes of the HyTAGs resulted in the shrinking of the cool temperate forests and the expansion of the warm temperate and subtropical forests, with different rates in each climate change scenario. The classification accuracy $(\mathrm{CA})$ and prediction probability $(\mathrm{PrP})$ values of 32.4 and $35.0 \%$, respectively, validated the accuracy of HyTAGs as being relatively predictive of overall distributions of cooltemperate (HyTAG-A), temperate (HyTAG-B), and warm-temperate (HyTAG-C) mixed forests.
\end{abstract}

KEY WORDS: Forest cover distribution - Climate change $\cdot$ Climatic controllers $\cdot$ Precipitation effectiveness index $\cdot$ Warmth index $\cdot$ Minimum temperature index

Resale or republication not permitted without written consent of the publisher

\section{INTRODUCTION}

The forest ecosystem has been recognized as an important factor in climatic processes due to its contribution to heat and moisture fluxes (Arris \& Eagleson 1989). Conversely, climatic variables are major abiotic factors in the phenological, physiological, and geographical status of the forest ecosystem (Stephenson 1990, Prentice et al. 1992, Neilson 1995, Box 1996). Climatic changes could result in the distributional and functional alteration of the forest ecosystem (Neilson \& Marks 1994, Box 1996, Kong 2005).
Therefore, one of the significant topics in ecological and biogeographical studies is to understand the responses of the forest ecosystem to its habitat condition changes (Arris \& Eagleson 1989, Neilson 1993, Lenihan et al. 2003, Laurent et al. 2004, Matsui et al. 2004a).

Among the many vegetation model studies (Cao \& Woodward 1998, Osborne et al. 2000, Bachelet et al. 2001, Watanabe et al. 2004) designed to link the rulebased and process-based models, Dynamic Global Vegetation Models (DGVMs) simulate the changes in the potential distribution of vegetation and its asso- 
ciated biogeochemical and/or hydrological fluxes due to climate change. DGVMs simulate the annual or monthly dynamics of ecosystem processes, and their temporal and spatial resolutions are varied depending on the time series of climate data and the given constraints of latitude, topography, and soil characteristics (Bachelet et al. 2001). The MAPSS-CENTURY (MC1) model of the US Department of Agriculture, was applied to evaluate the effects of climate change on the vegetation ecosystem of California (Lenihan et al. 2003, 2008). The Carbon Exchange between Vegetation, Soil, and Atmosphere (CEVSA) models of China predicted that the habitats of mixed forests and deciduous broad-leaved forests are likely to expand northward, and concluded that shrub and grasslands will become widespread in the southern part of China due to climate change (Yu et al. 2006).

Theoretically, DGVMs are applicable to both small regions and the entire globe (e.g. MC1: from $50 \mathrm{~m}$ to $350 \mathrm{~km}$; Bachelet et al. 2001), since their performance is determined by the spatial resolution of input data. However, they may not be suitable for a relatively small-scale region such as the Korean forest ecosystem. Kim et al. (2009) mentioned that DGVMs such as Holdridge (Kim \& Lee 2006), CEVSA (Lee et al. 2007a) and MC1 (Choi et al. 2010a) could not provide reliable results for Korea on a regional scale because they were mostly designed and tested on global or continental scales. For example, the MC1 model employed only 4 plant functional types (PFTs) in the simulation of the Korean forest ecosystem responses to climate change, and the tree classification thresholds of the MC1 were less sensitive for handling the relatively heterogeneous Korean territory compared to the entire globe (Choi et al. 2010a). Similarly, due to the spatial heterogeneity of forest ecosystems in European countries, Laurent et al. (2004) reported that the combination of the PFTs used for the DGVMs lacks accuracy on a regional scale. According to Riera et al. (1998), the spatial heterogeneity in forest ecosystems is manifested by microenvironments or natural/human-related disturbances on a small or medium (regional) scale whereas large (global) scale models usually employ the mean vegetation distribution, constrained by global climate and elevation. Therefore, it is necessary to optimize approaches for modeling forest distribution on a regional scale (e.g. the middle scale between individual plots and the entire globe). The goal of this study was to simulate and predict the potential forest vegetation distribution using the correlated climatic variables on a smaller scale, compared to those encountered at a global level.
By using a newly suggested approach, the PFTs were re-determined using the correlated climatic variables (Mather \& Yoshioka 1968, Woodward 1987, Woodward et al. 2004). The potential forest distribution was predicted along the hydrological and thermal gradient indices such as the Precipitation Effectiveness Index (PEI) (Thornthwaite 1948), Warmth Index (WI) (Kira 1945, Yim 1977a,b, Fang \& Yoda 1989, 1990a,b) and Minimum Temperature of the Coldest Month (MTC) (Neilson 1995, Matsui et al. 2004a,b, Horikawa et al. 2009). In terms of hydrological gradient, the PEI has been used to classify the climatic zone corresponding to forest ecosystem types (Thornthwaite 1948) and to state the relationship between the hydrological index and vegetation regimes (Mather \& Yoshioka 1968, McCabe \& Wolock 1992). Even though the study of Usman et al. (1999) was not directly related to forest ecosystem distribution, their results could be significant in assuming that the PEI would indirectly affect the distribution of tree species, because the productivity of each tree species was affected by PEI. On the other hand, in terms of thermal gradient, the WI has long been recognized as an important index for predicting potential vegetation distributions (Kira 1945, Yim 1977a, Fang \& Yoda 1990a). Recently, extreme cold, or minimum winter temperature, was mentioned as the principal factor determining the northern limits of the natural tree habitat because it relates to injury or death of organs such as twigs (Matsui et al. 2004a,b, Sakai 1978, Sakai et al. 1979). Strimbeck et al. (2007) stated that an understanding of the degree and mechanisms of low temperature tolerance is important in predicting the effects of climate change on tree and forest health and productivity. Therefore, some studies used both the WI and MTC to predict the distribution change of particular species due to climate change (Matsui et al. 2004a,b, Choi et al. 2010b).

In Korea, the WI was applied to demonstrate the reasonable spatial distribution of forest vegetation for 4 groups: subalpine, cool-temperate, warmtemperate deciduous and warm-temperate evergreen (Yim 1977a,b, Yang \& Shim 2007). Choi et al. (2010b) have suggested the Thermal Analogy Group (TAG) model, using both the WI and the MTC index (MTCI). However, no trials applying both the hydrological and thermal indices, such as PEI, WI, and MTCI, have been conducted in Korea to predict the spatial distribution of forest vegetation. This study was therefore designed to develop a Korea-specific forest vegetation distribution model. The purpose of this study was to simulate the potential forest distribution in Korea using the optimal habitat ranges of 
both the hydrological and thermal indices, i.e. PEI, WI, and MTCI, in the manner of the static bioclimatic classification.

\section{MATERIALS AND METHODS}

\subsection{Study area and data preparation}

\subsubsection{Study area}

The study area comprised all of South Korea, $33^{\circ} 09^{\prime}$ to $38^{\circ} 45^{\prime} \mathrm{N}$, and $124^{\circ} 54^{\prime}$ to $131^{\circ} 06^{\prime} \mathrm{E}$. This area was presented as raster data with a spatial resolution of $0.01^{\circ}(\sim 1 \mathrm{~km})$. The Taebaek Mountain Range rises to over $1500 \mathrm{~m}$ on the eastern side of Korea. From the Taebaek Mountain Range, the Sobaek Mountain Range runs from the northeast to the southwest. In the central zone, moderately high mountains dominate the landscape. Lowlands are found mainly along the western region of the study area (Fig. 1) (NGII 2007). Evergreen needle-leaved forests (mainly Pinus densiflora), deciduous broad-leaved forests (mainly Quercus spp.), and mixed forests occupied $42 \%$ $\left(28600 \mathrm{~km}^{2}\right), 26 \%\left(16590 \mathrm{~km}^{2}\right)$, and $29 \%\left(18530 \mathrm{~km}^{2}\right)$, respectively, of the total forest area in 2008 (KFS 2009). vided climatic data, including monthly mean temperature, mean daily minimum temperature and accumulated precipitation obtained from 75 weather stations over South Korea, for the period 1971 to 2000. These data were interpolated with a $0.01^{\circ}$ grid size ( 1 km) using Kriging and Inverse Distance Squared Weighting in consideration of the absolute temperature and precipitation lapse rate by elevation (Lull \& Ellison 1950, Yun et al. 2001, Cho \& Jeong 2006, Lee et al. 2007b, Smith 2007, Park \& Jang 2008). In addition, future climatic data were predicted under 3 climate change scenarios, B1, A1B, and A2 (Special Report on Emission Scenarios; IPCC 2000). The National Institute of Meteorological Research of Korea provided the A1B future climate anomalies with a $0.2432^{\circ}$ grid size $(27 \mathrm{~km})$ using the Fifth-Generation National Center for Atmospheric Research (NCAR) / Penn State Mesoscale Model (MM5) with the ECHO-G initial boundary from Max Planck Institute (Min et al. 2006, Cha et al. 2007). The Korea Environment Institute provided the B1 and A2 future climate anomalies with $20 \mathrm{~km}$ spatial resolution using the Seoul National University Regional Climate Model (SNURCM) with CCSM3 initial boundary from NCAR (Cha \& Lee 2009). These datasets were resampled to fit on $0.01^{\circ}$ spatial resolution in the WGS-84 coordination system (Lee et al. 2007b).

\subsubsection{Actual vegetation map}

The actual vegetation map of Korea was produced by the Ministry of Environment of Korea in 2008. It was based on both remote sensing (aerial and

The temporal resolutions of the static simulations were (1) $30 \mathrm{yr}$ of past (1971 to 2000), and (2) $20 \mathrm{yr}$ of near future (2046 to 2065) and far future (2080 to 2099). The Korea Meteorological Administration pro-

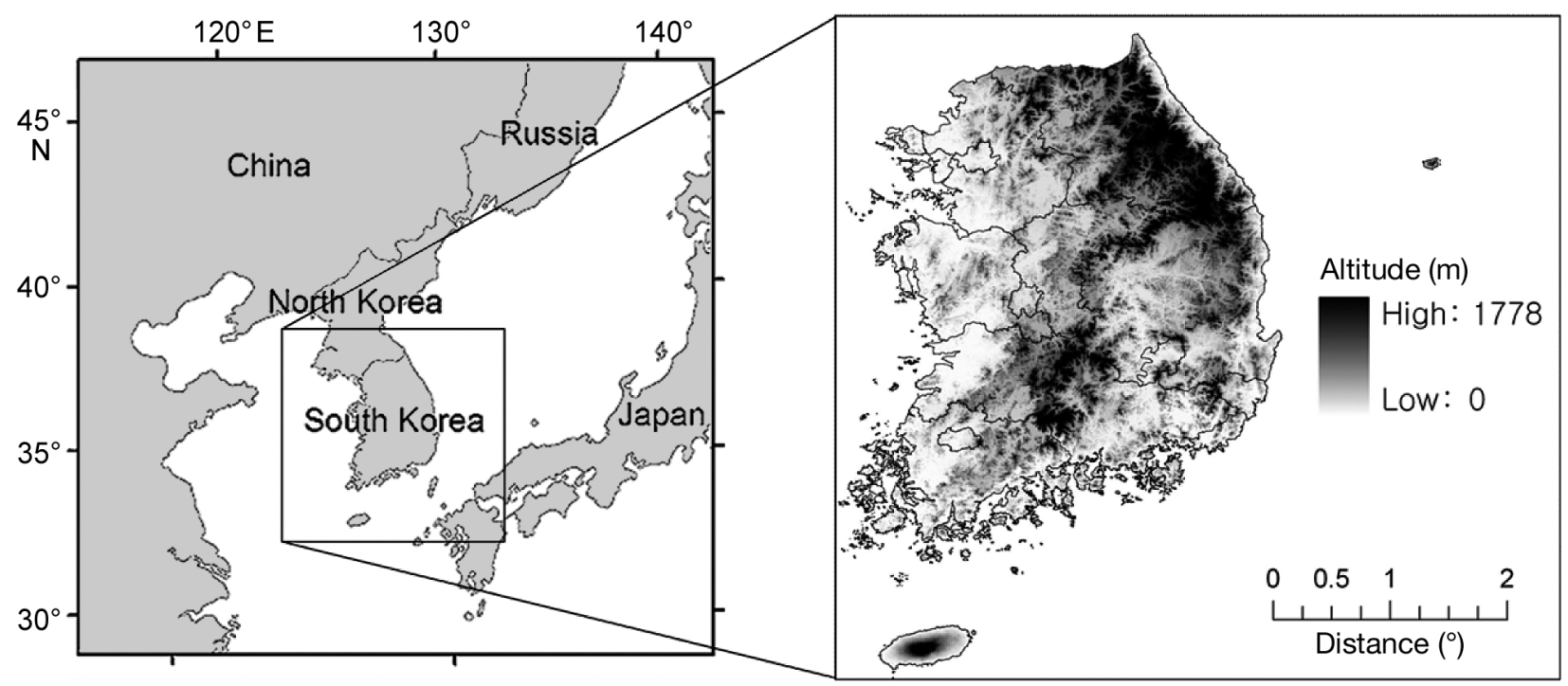

Fig. 1. Study area 
satellite imagery) techniques and field surveys. First, the boundaries of the forest communities were delimited from the remotely sensed data. Then, the forest community level classification was conducted by ground truth surveys, and its boundary was rectified by experts in ecology and forestry. The map of actual vegetation, representing 229 vegetation communities, was projected in a 1:50 000 scale using a National GIS Database Projection (KEI 2008). In this study, we used only the natural forest communities and excluded the anthropogenically affected forest communities. This approach was employed in a previous study by Matsui et al. (2004b), who assumed that the natural distribution of Fagus crenata could be obtained from the actual vegetation map (aerial photograph and field survey based), after excluding anthropogenic vegetation types such as plantation forests, agricultural lands and urban areas. In this study, the distributional patterns of major tree species were extracted from the actual vegetation map, and their boundaries were modified by the ArcGIS tool (minimum buffer zone [r/2]: $0.0071^{\circ}$, where $\mathrm{r}^{2}=2 \times$ $0.01^{2}$ ) to envelop the minimum size of the climatic data pixels $\left(\sim 1 \mathrm{~km}^{2}\right)$. The major tree species were divided into 7 evergreen needle-leaved (EN), 1 deciduous needle-leaved (DN), 17 deciduous broad-leaved (DB), and 3 evergreen broad-leaved (EB) species communities. Then, we assigned a species code for each tree species by category and alphabetical order (Table 1).

\subsection{Hydrological and thermal indices}

\subsubsection{Precipitation-Evaporation Index (PEI)}

According to Thornthwaite (1948), the PEI is a measure of the long-range effectiveness of precipitation in promoting plant growth for a given location. The PEI is equal to the sum of the monthly PE ratios (monthly precipitation/monthly evaporation amounts). The PE ratio is an empirical expression devised for numerically classifying climates on the basis of precipitation and evaporation for a given locality and month (see Eq. 1). The PEI has been used to classify the climatic zone corresponding to forest ecosystem types (Thornthwaite 1948) and to clarify the relationship between hydrological index and vegetation
Table 1. Major tree species and codes from the actual vegetation map (28 tree species). EN: evergreen needle-leaved trees, DN: deciduous needle-leaved trees, DB: deciduous broad-leaved trees, EB: evergreen broad-leaved trees

\begin{tabular}{|c|c|c|c|}
\hline $\begin{array}{l}\text { Tree } \\
\text { type }\end{array}$ & $\begin{array}{l}\text { Species } \\
\text { code }\end{array}$ & English name & Scientific name \\
\hline EN & $\begin{array}{l}\text { A01 } \\
\text { A02 } \\
\text { A03 } \\
\text { A04 } \\
\text { A05 } \\
\text { A06 } \\
\text { A07 }\end{array}$ & $\begin{array}{l}\text { Korean fir } \\
\text { Khingan fir } \\
\text { Japanese red pine } \\
\text { Korean pine } \\
\text { Pitch pine } \\
\text { Japanese black pine } \\
\text { Japanese yew }\end{array}$ & $\begin{array}{l}\text { Abies koreana } \\
\text { Abies nephrolepis } \\
\text { Pinus densiflora } \\
\text { Pinus koraiensis } \\
\text { Pinus rigida } \\
\text { Pinus thunbergii } \\
\text { Taxus cuspidata }\end{array}$ \\
\hline DN & B01 & Japanese larch & Larix kaempferi \\
\hline DB & $\begin{array}{l}\mathrm{C} 01 \\
\mathrm{C} 02 \\
\mathrm{C} 03 \\
\mathrm{C} 04 \\
\mathrm{C} 05 \\
\mathrm{C} 06 \\
\mathrm{C} 07 \\
\mathrm{C} 08 \\
\mathrm{C} 09 \\
\mathrm{C} 10 \\
\mathrm{C} 11 \\
\mathrm{C} 12 \\
\mathrm{C} 13 \\
\mathrm{C} 14 \\
\mathrm{C} 15 \\
\mathrm{C} 16 \\
\mathrm{C} 17\end{array}$ & $\begin{array}{l}\text { Mono maple } \\
\text { Ermans birch } \\
\text { Red-leaved hornbeam } \\
\text { Yeddo hornbeam } \\
\text { Turczaninow hornbeam } \\
\text { Japanese chestnut } \\
\text { Giant dogwood } \\
\text { Japanese beech } \\
\text { Mandshurica walnut } \\
\text { Oriental chestnut oak } \\
\text { Oriental white oak } \\
\text { Daimyo oak } \\
\text { Mongolian oak } \\
\text { Konara oak } \\
\text { Cork oak } \\
\text { Black locust } \\
\text { Japanese zelkova }\end{array}$ & $\begin{array}{l}\text { Acer mono } \\
\text { Betula ermanii } \\
\text { Carpinus laxiflora } \\
\text { Carpinus tschonoskii } \\
\text { Carpinus turczaninovii } \\
\text { Castanea crenata } \\
\text { Cornus controversa } \\
\text { Fagus engleriana (crenata) } \\
\text { Juglans mandshurica } \\
\text { Quercus acutissima } \\
\text { Quercus aliena } \\
\text { Quercus dentata } \\
\text { Quercus mongolica } \\
\text { Quercus serrata } \\
\text { Quercus variabilis } \\
\text { Robinia pseudoacacia } \\
\text { Zelkova serrata }\end{array}$ \\
\hline EB & $\begin{array}{l}\text { D01 } \\
\text { D02 } \\
\text { D03 }\end{array}$ & $\begin{array}{l}\text { Common camellia } \\
\text { Japanese chinquapin } \\
\text { Japanese evergreen oak }\end{array}$ & $\begin{array}{l}\text { Camellia japonica } \\
\text { Castanopsis sieboldii } \\
\text { Quercus acuta }\end{array}$ \\
\hline
\end{tabular}

regimes (Mather \& Yoshioka 1968, McCabe \& Wolock 1992). In these studies, only the annual precipitation was applied, without consideration for the seasonal variation of hydrological indices, e.g. spring, summer, and winter precipitation. In the distribution prediction of the MC1 model, the relative mixture of the EN, DB, and EB life-forms is determined by both the growing season precipitation (GSP) and MTCI (Bachelet et al. 2001). The GSP is calculated as the mean monthly precipitation of the 3 warmest months of the year (June, July, and August in Korea). This climatic variable was originally suggested by Neilson $(1993,1995)$ to separate the needle-leaved forests favored by dry summers.

Stephenson $(1990,1998)$ employed the annual actual evapotranspiration (AET), which considers both energy (temperature) and water (precipitation) availability as an important physiological index for vegetation distribution. However, the annual AET is not 
incorporated with seasonal variation, whereas the establishment and/or radial growth of tree species are associated with the seasonal climatic features. For example, a spring drought increases the mortality of pine seedlings (Lee et al. 2004), while precipitation during spring limits the growth of Pinus densiflora (Park \& Yadav 1998). Therefore, we decided to use the seasonal PEIs as the main hydrological indices rather than using the AET related to the annual precipitation for the prediction of forest distribution. We modified and separated the PEIs for annual (January to December), spring (March to May), summer (June to August), and winter (December to February) periods in Eqs. (2-5):

$$
\begin{aligned}
& \mathrm{PE} \text { ratio }(i)=0.165 \times\left[\mathrm{P}_{i} /\left(T_{i}+12.2\right)\right]^{10 / 9} \\
& \mathrm{PEI}_{\text {Annual }}=10 \times \sum_{i=1}^{12} \mathrm{PE} \text { ratio }(i) \\
& \mathrm{PEI}_{\text {Spring }}=40 \times \sum_{i=3}^{5} \mathrm{PE} \text { ratio }(i) \\
& \mathrm{PEI}_{\text {Summer }}=40 \times \sum_{i=6}^{8} \mathrm{PE} \text { ratio }(i) \\
& \mathrm{PEI}_{\text {Winter }}=40 \times \sum_{i=12}^{2} \mathrm{PE} \text { ratio }(i)
\end{aligned}
$$

where $i$ is the number of the month (from $1=$ January to $12=$ December), $P_{i}$ is the normal monthly precipitation in $\mathrm{mm}$, and $\mathrm{T}_{i}$ is the normal monthly temperature in ${ }^{\circ} \mathrm{C}$. All temperatures $<-2^{\circ} \mathrm{C}$ are given the value of $-2^{\circ} \mathrm{C}, \mathrm{PE}$ ratios $>40$ are counted as 40 (Setzer 1946)

\subsubsection{Thermal indices (WI and MTCI)}

WI of Kira (1945) was prepared for each pixel using Eq. (6), which counts the annual sum of positive differences between monthly means and $5^{\circ} \mathrm{C}$.

$$
\mathrm{WI}=\Sigma(t-5)
$$

where $t$ is the monthly mean temperature $>5^{\circ} \mathrm{C}$.

As another thermal index, the MTCI was employed (Bachelet et al. 2001). Following the logic of Neilson (1995), the MTC was converted using Eq. (7).

$$
\left.\mathrm{MTCI}=\left[\left(\mathrm{MTC}-t_{\mathrm{mid}}\right) /\left(t_{\mathrm{hi}}-t_{\mathrm{mid}}\right)\right] \times 100\right)
$$

where $t_{\mathrm{hi}}$ and $t_{\text {mid }}$ are 18.0 and $1.5^{\circ} \mathrm{C}$, respectively.

Both the WI and MTCI are important thermal indices because they are correlated to the effective heat for plants and freezing resistance of tree species, respectively (Kira 1945, Neilson 1995). Matsui et al. $(2004 \mathrm{a}, \mathrm{b})$ mentioned that the WI and MTC were important indices to evaluate the relationships of climatic factors to the presence/absence of Fagus crenata in their Classification Tree Model. Choi et al. (2010b) also used both WI and MTCI to predict the effect of climate change on the potential forest distribution of South Korea.

\subsection{Optimal habitat PEI, WI, and MTCI ranges}

We estimated the optimal habitat PEI, WI, and MTCI ranges for major tree species using the prepared hydrological and thermal indices and the actual habitat boundaries of each tree species (remote sensing-based). Based on the PEI, WI, and MTCI distribution of the past (1971 to 2000), we first extracted the PEI, WI, and MTCI within the actual habitat boundaries of each species. Then, the spatially extracted PEI, WI, and MTCI were plotted as the normal distribution curves. The optimal habitat PEI, WI, and MTCI ranges were defined by cutting the maximum and minimum ends $(<11.5 \%)$ of the whole habitat ranges for each species. Therefore, $77 \%$ of the whole distribution of the PEI, WI, and MTCI was determined as the optimal habitat range. Fig. 2a depicts the optimal habitat WI ranges of Pinus koraiensis (whole range: 33.4 to $99.9^{\circ} \mathrm{C}$, optimal range: 46.5 to $87.1^{\circ} \mathrm{C}$ ) and Quercus aliena (whole range: 64.9 to $113.6^{\circ} \mathrm{C}$, optimal range: 82.1 to $99.6^{\circ} \mathrm{C}$ ). In a previous study, Yim (1977a) plotted the WI range for each tree species based on the frequency of its altitudinal distribution (field survey-based) and assumed that the curve generally follows the Gaussian distribution. Then, the optimal range of thermal distribution was determined as encompassing $77 \%$ of the recorded tree stands. Fang \& Yoda (1990b) prepared the distribution range curve of species using the relative frequency of its altitudinal distribution calculated in a field-based survey. They defined the optimal range of thermal distribution by cutting the maximum and minimum ends $(<5 \%$ each) of the whole distribution range for a species. With a normal distribution curve, the main distribution range for a species may cover $90 \%$ of the whole distribution.

In this study, we employed a 3D-matrix method and assigned the WI, MTCI, and PEI on the $x, y$, and $z$ axes, respectively. The box shape of ranges was prepared to delimit the habitats based on the optimal PEI, WI, and MTCI ranges for each tree species. As shown in Fig. 2b, optimal habitat ranges of each species have 9 explanatory variables, i.e. 1 center point and 8 corners of a 3D matrix: $x$-WI, $y$-MTCI, z-PEI. 


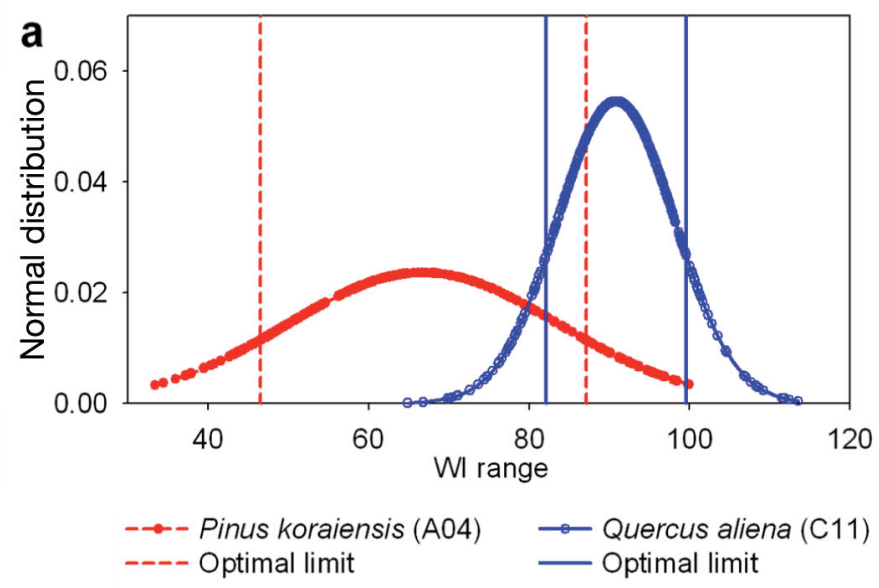

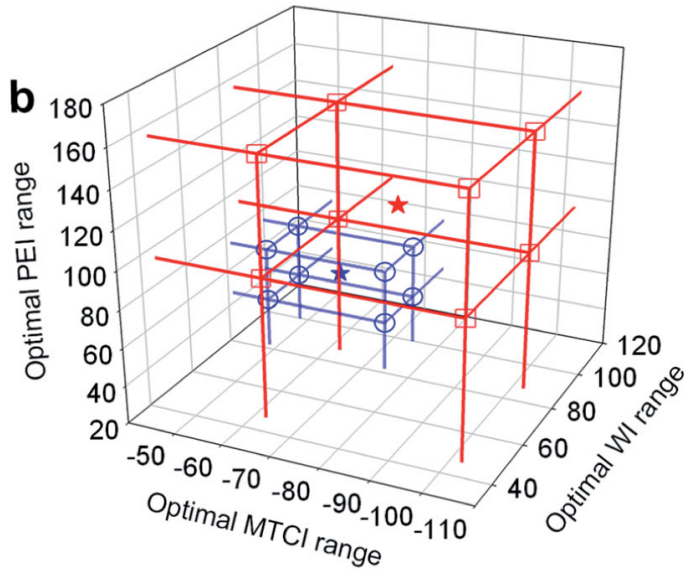

$\square$ Optimal range limiting points of $P$. koraiensis (A04) Optimal range limiting points of $Q$. aliena (C11) $\star$ Center point of A04

$\star$ Center point of $\mathrm{C} 11$

Fig. 2. Pinus koraiensis and Quercus aliena. (a) Optimal Warmth Index (WI) habitat ranges and (b) box shaped ranges of WI, Minimum Temperature of the Coldest Month Index (MTCI) and Precipitation-Evaporation Index (PEI)

\subsection{Potential distribution of major tree species}

\subsubsection{Binary logistic selection of optimal habitat}

In predicting the potential distribution of major tree species, we first assumed that the optimal ranges of WI, MTCI, and PEI were independently applied to spatially extract potential habitat boundaries for each tree species based on the binary logistic selection. In other words, we assigned 1 on a grid where its values of hydrological and thermal indices were within the optimal habitat ranges, and assigned 0 otherwise. Second, both WI and MTCI were assumed to be the confident bioclimatic limiting factor related to potential distribution of major tree species. Also, it was required to find appropriate seasonal PEI (i.e. one of annual, spring, summer, and winter) for each tree species as a complementary limiting factor. As shown in Fig. 3, for example, the optimal ranges of each bioclimatic limiting factor could indicate potential boundaries for each limiting factor. Then, spatially overlapped grids by extensions of 3 limiting factors (e.g. WI, MTCI, and one of the PEIs; Fig. 3b-c,e) were assumed as the potential distribution of Quercus mongolica (Fig. 3h).

\subsubsection{Validation 1}

The potential distributions of major tree species based on WI, MTCI, and seasonal PEIs were first verified with actual habitat boundaries of each species using the Classification Accuracy (CA). Matsui et al. (2004a) used the CA (Eq. 8) of Iverson \& Prasad (1998) to assess their result of prediction on the forest distribution. A CA value close to $100 \%$ indicates that the result of predicted distribution can confidently simulate the distribution of each tree species. Similar to the study of Matsui et al. (2004a), anthropogenically affected areas were excluded in verification.

$$
\mathrm{CA}=\left[S_{\mathrm{both}} /\left(S_{\mathrm{act}}+S_{\text {pred }}-S_{\mathrm{both}}\right)\right] \times 100
$$

where $S_{\text {both }}$ is the area identified as containing species of interest in both the actual vegetation map from the Ministry of Environment and the simulated results, $S_{\text {act }}$ is the area identified in the actual vegetation map and $S_{\text {pred }}$ is the area identified in the simulated results.

We selected appropriate seasonal PEI for each species according to the CA scores. For instance, the actual distribution and one of predicted potential distributions of Quercus mongolica a shown in Fig. 3a,h. The combination of WI, MTCI, and spring PEI produced a higher CA score in potential distribution of Q. mongolica than combinations of WI, MTCI, and other seasonal PEIs.

\subsection{Defining new PFTs (HyTAGs) and prediction of potential forest distribution}

\subsubsection{Hierarchical clustering analysis (HCA)}

The estimated optimal habitat ranges based on WI, MTCI, and selected seasonal PEI were employed to define new PFTs, i.e. the so-called hydrological and thermal analogy groups (HyTAGs). Based on the inte- 

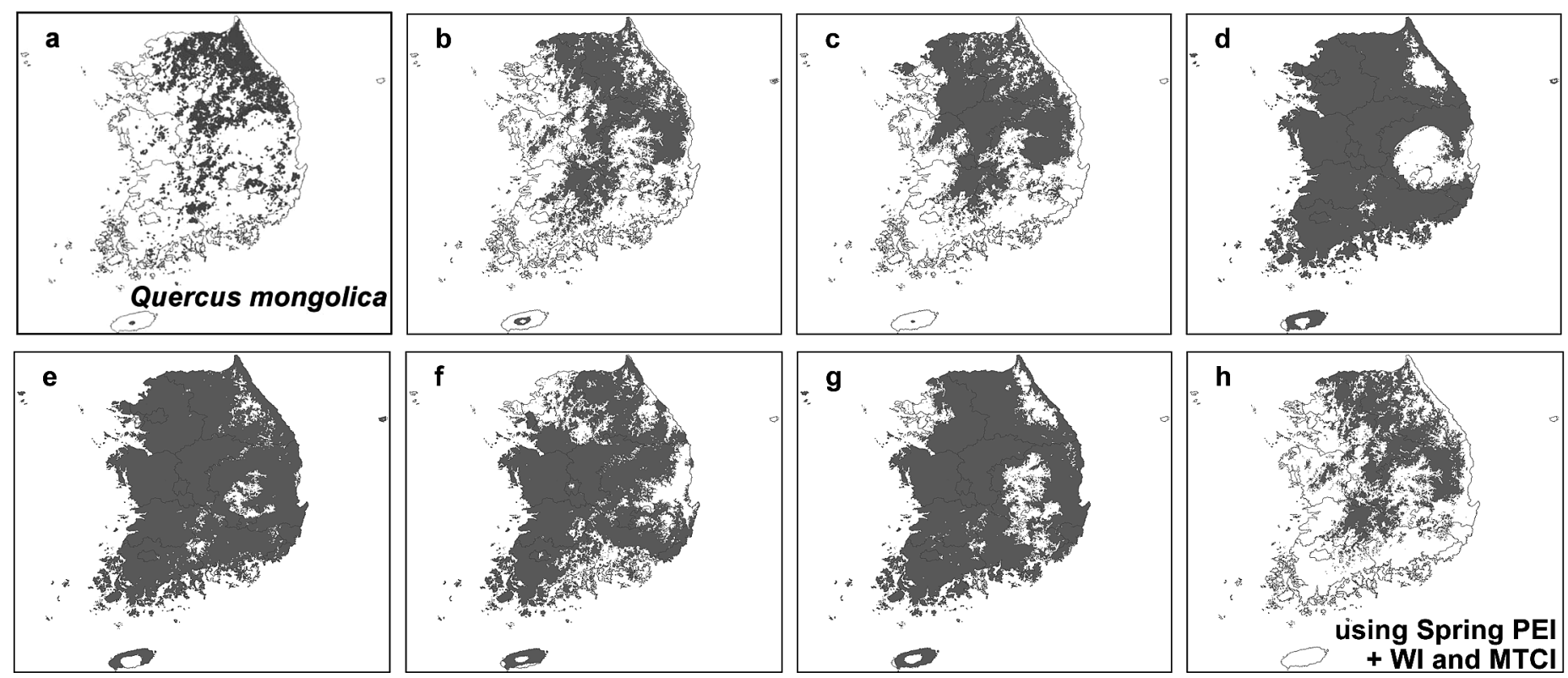

Fig. 3. (a) Quercus mongolica. Actual distribution and optimal habitat, (b) WI, (c) MTCI, and (d) annual, (e) spring, (f) summer, and $(\mathrm{g})$ winter PEI distributions, and $(\mathrm{h})$ predicted potential distribution using the past WI, MTCI and spring PEI distribution. See Fig. 2 for definitions

grated optimal habitat ranges for each species, the HyTAGs were defined by following the analogues in the optimal PEI, WI, and MTCI ranges. The hierarchical clustering analysis (HCA) with 9 explanatory variables (i.e. 1 center point and 8 corners of 3D matrix) for each species was applied using the single linkage clustering in SAS v9.2 for Windows (SAS 2009). This approach is very useful to describe the PFT along environmental gradients such as temperature and precipitation (Chapin et al. 1996, Gavilan 2005).

The HCA first produced 3 primary clusters (HyTAG-A, -B, and -C), and then, intermediate clusters (HyTAG-AB and -BC) were defined by the intersections between spatial extensions of relevant primary clusters. Since not all study areas were explained by listed major tree species, we assumed that HyTAG-N, $-\mathrm{T}$, and -S were simply defined by WI criteria of Yim (1977a). Finally, the defined 8 HyTAGs were employed to predict the potential forest distributions of the past (1971-2000), near future (20462065), and far future (2080-2099).

\subsubsection{Validation 2}

If the actual habitat of the tree species is relatively smaller than the predicted habitat, the CA could be estimated with very low accuracy. Therefore, we also computed the prediction probability (PrP) to verify the HyTAG (Eq. 9). The PrP is an index showing how a large area in the actual vegetation map corresponds to the simulated results.

$$
\operatorname{PrP}=\left(S_{\text {both }} / S_{\text {act }}\right) \times 100
$$

where $S_{\text {both }}$ and $S_{\text {act }}$ are defined as in Eq. (8).

As in $\mathrm{CA}$, the PrP values close to $100 \%$ indicate that the result of predicted distribution can confidently simulate the past forest distribution. In this study, the reference distributions for HyTAG validation were the aggregated areas of the single tree species relevant to each HyTAG. Both CA and PrP were estimated only for overall distributions of HyTAG-A, $-B$, and $-C$. The overall scheme of the HyTAG model is described in Fig. 4.

\section{RESULTS AND DISCUSSION}

\subsection{PEI, WI, and MTCI distribution}

The PEI distribution ranges for the annual, spring, summer, and winter periods are given in Table 2. Overall, the annual PEI is predicted to slightly increase in the near future (2046-2065) and in the far future (2080-2099) under the IPCC A1B scenario (Table 2, Fig. S1a in the supplement at www.int-res. com/articles/suppl/c049p229_supp.pdf).

The WI distribution for Korea in past years (19712000) according to Yim (1977a) corresponded to the criteria of subalpine species $\left(30\right.$ to $\left.70^{\circ} \mathrm{C}\right)$, cool- 


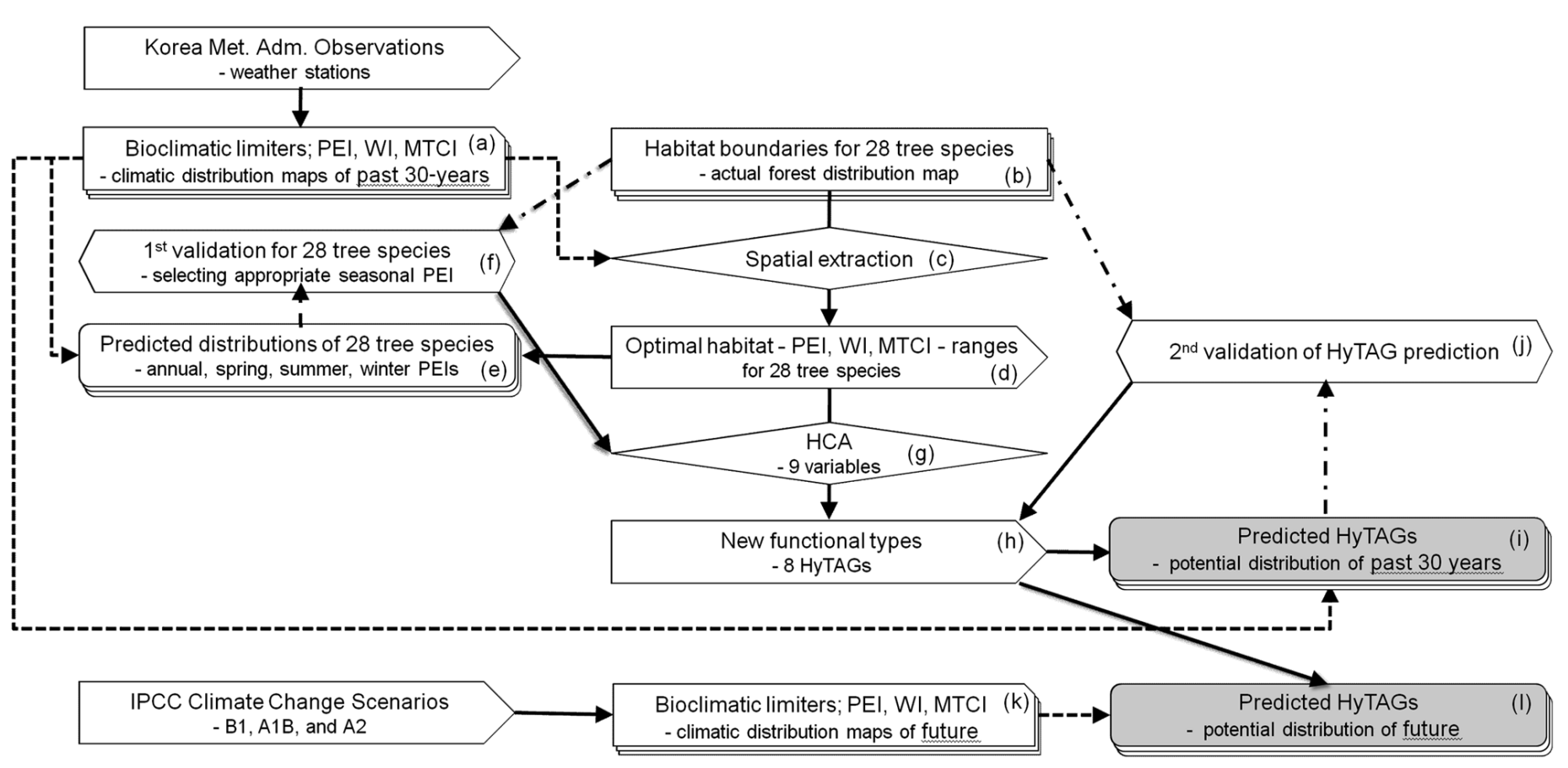

Fig. 4. Overall hydrological and thermal analogy groups (HyTAG) model scheme. $(\mathrm{a}, \mathrm{k})$ Input from geographic maps; (b) validation reference; $(c, g)$ grouping and extraction (function); $(d, h)$ input data and scenarios, parameters (habitat range and PFTs) from KMA observations and IPCC scenarios; $(e, i, l)$ output results (unshaded: intemediate, shaded: final); (f,j) validations. HCA: Hierarchical clustering analysis; see Fig. 2 for other abbreviations

temperate species $\left(50\right.$ to $\left.90^{\circ} \mathrm{C}\right)$, warm-temperate deciduous $\left(80\right.$ to $\left.100^{\circ} \mathrm{C}\right)$ and evergreen species zone $\left(100\right.$ to $\left.120^{\circ} \mathrm{C}\right)$. This WI distribution characteristic was probably related to the latitudinal and altitudinal patterns, which are correlated to the dominant tree species of forest ecosystems (Ohsawa 1993, Takyu et al. 2005). Overall, the WI will increase in the future under IPCC A1B scenario in the near and the far future (Table 2, Fig. S1b). The upper limits of the WI in the future could not be completely explained by the above categories, but according to Fang \& Yoda (1990b), they were covered by vegetation zones such as a warm-temperate EB forest zone (90 to $\left.175^{\circ} \mathrm{C}\right)$, and a southern warm-temperate subzone $\left(135\right.$ to $\left.175^{\circ} \mathrm{C}\right)$.

The MTCI distribution in Korea in past years had a wider range than that of the WI. In addition, the MTCI had narrower fluctuations in the upper limit of values than the WI, due to climate change. The MTCI will increase in the future under the IPCC A1B scenario (Table 2, Fig. S1c).

In terms of the spatial distributions of the PEI, WI and MTCI in Korea, their past distribution patterns were similar to the topographic features of Korea. The PEI values in the southeastern inland and in the southern coastal area were relatively low and relatively high, respectively. In addition, the WI and MTCI tended to be lower in the northeast and higher in the southwest, which corresponded to the elevation. The future effects of climate change under IPCC B1 and A2 scenarios on the changes of the WI, MTCI, and seasonal PEIs are described in Table 2. Generally, both the WI and MTCI will tend to increase in the future, and the higher WI and MTCI zones in the southwest will expand to the northeast. Change rates of mean PEI, WI, and MTCI depend on the IPCC climate change scenarios.

\subsection{PEI, WI, and MTCI ranges of optimal habitat}

The results revealed the optimal habitat PEI, WI, and MTCI range for each tree species. The optimal spring and winter PEI ranges exhibited a relatively large variation among the tree species, compared to the relatively small variation of the optimal annual and summer PEI ranges. The optimal annual and summer PEIs showed opposite variation trends among species. For example, the optimal habitat of Pinus densiflora (species code A03) occupied a relatively dry annual PEI, but wet summer PEI, whereas the optimal habitats of Abies koreana were in a relatively wet annual PEI, but dry summer PEI. As shown in a previous study, Fagus crenata has a dry summer 
Table 2. Warmth Index (WI), Minimum Temperature of the Coldest Month Index (MTCI), and seasonal Precipitation Effectiveness Index (PEI) distribution ranges in Korea by IPCC B1, A2, and A1B climate change scenarios. Periods: Past (1971-2000), Near future: 2046-2065; Far future: 2080-2099. Parentheses: $($ mean $\pm \mathrm{SD})$

\begin{tabular}{|c|c|c|}
\hline Period & Scenario & Range (mean $\pm \mathrm{SD}$ ) \\
\hline \multicolumn{3}{|l|}{ WI $\left({ }^{\circ} \mathbf{C}\right)$} \\
\hline Past & & $33.0-136.7 \quad(92.9 \pm 14.5)$ \\
\hline Near future & B1 & $41.1-152.3(105.1 \pm 15.6)$ \\
\hline Near future & $\mathrm{A} 2$ & $45.7-158.8(111.5 \pm 16.1)$ \\
\hline Near future & A1B & $47.0-163.4(113.3 \pm 16.4)$ \\
\hline Far future & B1 & $42.3-153.7(106.6 \pm 15.8)$ \\
\hline Far future & A2 & $52.0-174.2(122.8 \pm 17.7)$ \\
\hline Far future & A1B & $55.1-180.2(127.3 \pm 17.9)$ \\
\hline \multicolumn{3}{|l|}{ MTCI } \\
\hline Past & & $-137.6-17.8(-55.1 \pm 21.4)$ \\
\hline Near future & B1 & $-119.2-25.0(-41.6 \pm 19.8)$ \\
\hline Near future & A2 & $-132.1-25.7(-46.6 \pm 21.6)$ \\
\hline Near future & A1B & $-121.6-30.6(-40.5 \pm 21.0)$ \\
\hline Far future & B1 & $-128.5-24.7(-46.3 \pm 21.1)$ \\
\hline Far future & A2 & $-108.3-36.2(-26.0 \pm 17.7)$ \\
\hline Far future & $\mathrm{A} 1 \mathrm{~B}$ & $-108.4-39.2(-28.6 \pm 20.2)$ \\
\hline \multicolumn{3}{|c|}{ Annual PEI $\left(\mathbf{m m}^{\circ} \mathbf{C}^{-1}\right)$} \\
\hline Past & & $65.7-299.7 \quad(93.5 \pm 13.6)$ \\
\hline Near future & B1 & $80.7-253.3(107.5 \pm 12.5)$ \\
\hline Near future & A2 & $77.5-246.0(104.7 \pm 11.8)$ \\
\hline Near future & A1B & $77.9-232.8(106.2 \pm 12.3)$ \\
\hline Far future & B1 & $74.1-225.2(100.1 \pm 11.4)$ \\
\hline Far future & $\mathrm{A} 2$ & $72.4-228.5 \quad(99.4 \pm 12.5)$ \\
\hline Far future & $\mathrm{A} 1 \mathrm{~B}$ & $72.5-228.0(100.1 \pm 12.9)$ \\
\hline \multicolumn{3}{|l|}{ Spring PEI } \\
\hline Past & & $57.7-523.2 \quad(87.3 \pm 22.2)$ \\
\hline Near future & B1 & $70.5-411.9(109.4 \pm 22.5)$ \\
\hline Near future & $\mathrm{A} 2$ & $78.7-409.2(107.5 \pm 21.3)$ \\
\hline Near future & A1B & $65.1-377.6 \quad(91.5 \pm 18.2)$ \\
\hline Far future & B1 & $66.0-325.5 \quad(92.0 \pm 17.2)$ \\
\hline Far future & A2 & $65.8-320.8 \quad(91.8 \pm 15.7)$ \\
\hline Far future & A1B & $62.1-369.2 \quad(88.1 \pm 18.3)$ \\
\hline \multicolumn{3}{|l|}{ Summer PEI } \\
\hline Past & & $61.8-249.6(149.8 \pm 21.1)$ \\
\hline Near future & B1 & $75.3-282.5(176.6 \pm 23.6)$ \\
\hline Near future & $\mathrm{A} 2$ & $69.0-270.3(166.9 \pm 25.5)$ \\
\hline Near future & $\mathrm{A} 1 \mathrm{~B}$ & $72.2-303.2(182.2 \pm 28.8)$ \\
\hline Far future & B1 & $75.4-255.5(159.7 \pm 22.8)$ \\
\hline Far future & A2 & $74.0-292.4(165.5 \pm 25.1)$ \\
\hline Far future & A1B & $64.9-257.1(153.8 \pm 24.2)$ \\
\hline \multicolumn{3}{|l|}{ Winter PEI } \\
\hline Past & & $31.5-393.9 \quad(62.1 \pm 21.1)$ \\
\hline Near future & B1 & $39.6-338.2 \quad(72.8 \pm 20.8)$ \\
\hline Near future & A2 & $37.4-301.7 \quad(62.1 \pm 15.5)$ \\
\hline Near future & A1B & $26.0-271.2 \quad(48.8 \pm 15.0)$ \\
\hline Far future & B1 & $33.6-311.2 \quad(62.0 \pm 17.5)$ \\
\hline Far future & A2 & $41.3-317.4 \quad(67.2 \pm 19.2)$ \\
\hline Far future & A1B & $32.4-281.4 \quad(57.5 \pm 18.8)$ \\
\hline
\end{tabular}

and wet winter PEI (Matsui et al. 2004a). Their model simulation predicted that the habitat of $F$. crenata was likely to be established in a region with high winter precipitation. Also, the EN tree species (A01 to A07) favor a habitat with a dry summer PEI, compared to the broad-leaved tree species (C01 to C17 and D01 to D03), in agreement with previous studies (Neilson 1993, 1995) (Fig. 5).

In terms of the optimal habitat of WI and MTCI, the ranges for each species exhibited similar trends. The species A01, A02, A07, and C02 tended to establish their habitat within low WI and MTCI conditions, whereas the species A06, C05, C10, D01, and D02 tended to be distributed in high WI and MTCI conditions. Newly defined optimal habitat WI and MTCI ranges were validated by previous studies (Yim 1977a, Fang \& Yoda 1990b, Choi et al. 2010b). As shown in Figs. $6 \&$, the estimated optimal habitat ranges were mostly within the ranges defined in earlier studies. For instance, the WI ranges of species A02, A07, C02, C08, C09, C10, and C15 were enveloped within the ranges of Yim (1977a) and Fang \& Yoda (1990b). In terms of the optimal MTCI ranges, more than $60 \%$ of the newly defined range was included in the previously defined MTCI ranges of Choi et al. (2010b). The newly defined optimal PEI, WI, and MTCI habitat ranges were applied to estimate the potential distributions of each tree species (Table S1). In particular, the optimal habitat ranges for Pinus densiflora, P. koraiensis, and Quercus spp. were confined to the northeastern inland in the far future (2080-2099) under IPCC B1, A2, and A1B scenarios.

\subsection{Selected seasonal PEI (Validation 1)}

In the first validation, the CA was applied to select appropriate seasonal PEI for major tree species. After excluding the anthropogenically affected areas, we estimated the total area of the actual habitat in the vegetation map from the Ministry of Environment of Korea (2008) and compared it with the predicted potential distribution for each tree species. Then, we extracted the area identified in both the actual vegetation map and the predicted area of each tree species. In the results, the CA varied depending on the seasonal PEIs and tree species. The minimum CA was $0.23 \%$ (Quercus dentata; using spring PEI), whereas the maximum CA was $72 \%$ (Fagus crenata; using summer PEI). In the particular simulation of Pinus densiflora, its potential static distribution was mostly associated with spring PEI rather than other seasonal PEIs. The CA of $P$. densiflora in spring was 


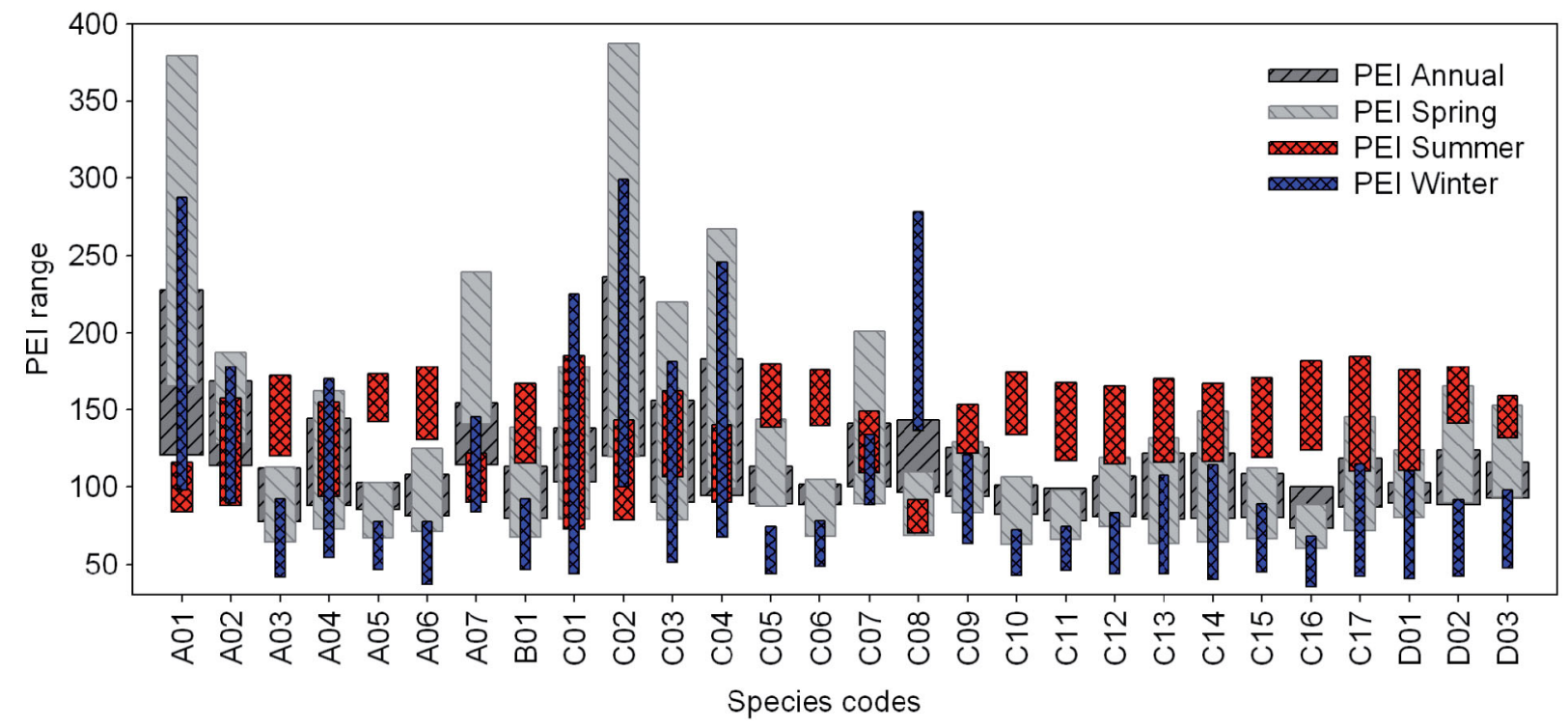

Fig. 5. Optimal habitat Precipitation-Evaporation Index (PEI) ranges for each tree species; see Table 1 for species names

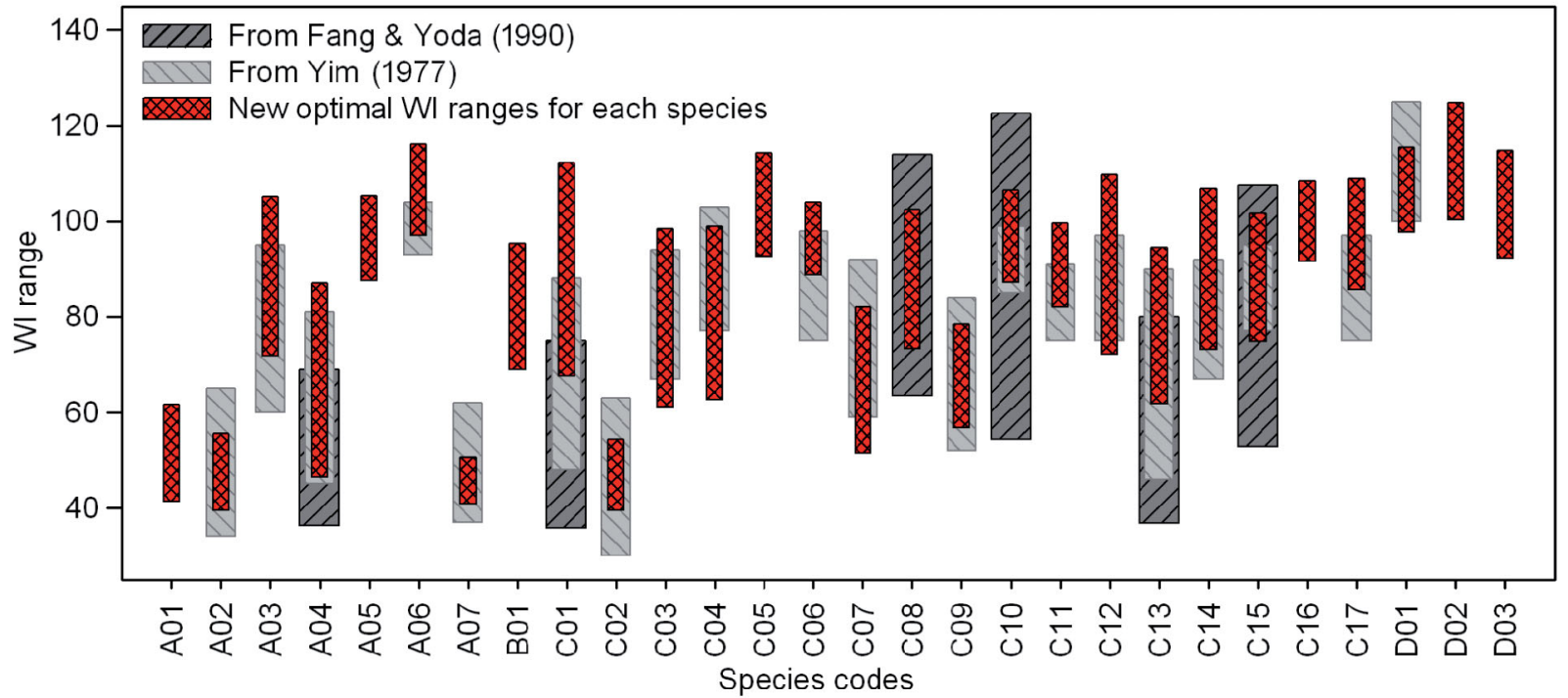

Fig. 6. Optimal habitat Warmth Index (WI) ranges for each tree species compared to previous studies; see Table 1 for species names

$53.6 \%$. This result was supported by previous studies showing that the establishment and growth of $P$. densiflora are strongly related to the spring precipitation and temperature (Park \& Yadav 1998, Lee et al. 2004). As shown in Table 3, we selected the appropriate seasonal PEI for each species based on the highest CA among seasonal PEIs.

\subsection{Defining range of HyTAGs (Validation 2)}

The HCA revealed 3 primary clusters (A, B, and C) with similar traits in optimal habitat WI, MTCI, and selected PEI ranges for each species (Fig. 8). In order to describe the potential forest distribution, 8 HyTAGs were prepared by grouping the tree species having similar habitat requirements. HyTAG-A (cool-temperate mixed forest in general) consisted of EN species Abies koreana, A. nephrolepis, Pinus koraiensis, and Taxus cuspidata, and DB species Betula ermanii, Cornus controversa and Juglans mandshurica. Kong (2004) classified the native Korean conifers as mountainous types and reported that their habitats are easily found in and around Mt. Odae, corresponding to the HyTAG-A region in past years. In addition, HyTAG-C (warm-temperate 


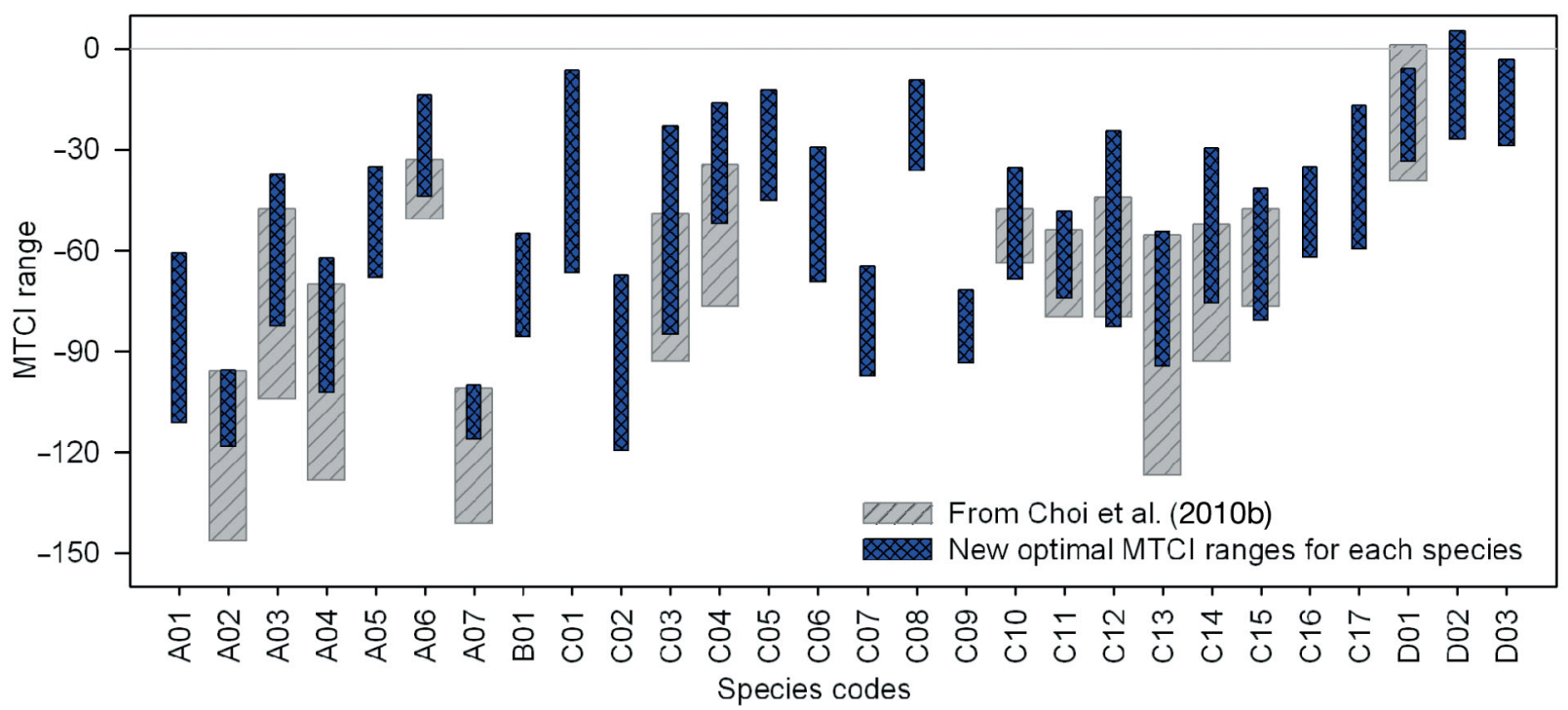

Fig. 7. Optimal habitat Minimum Temperature of the Coldest Month Index (MTCI) ranges for each species compared to Choi et al. (2010b); see Table 1 for species names

Table 3. Selected seasonal Precipitation-Evaportion Index (PEI) with the highest classification accuracy (CA). See Table 1 for species names

\begin{tabular}{|lcr|}
\hline Code & Selected & CA \\
& seasonal PEI & $(\%)$ \\
\hline A01 & Spring & 16.4 \\
A02 & Spring & 6.1 \\
A03 & Spring & 53.6 \\
A04 & Summer & 1.0 \\
A05 & Summer & 2.5 \\
A06 & Winter & 36.4 \\
A07 & Summer & 4.0 \\
B01 & Annual & 0.4 \\
C01 & Annual & 1.0 \\
C02 & Winter & 4.4 \\
C03 & Annual & 1.3 \\
C04 & Spring & 4.3 \\
C05 & Spring & 1.4 \\
C06 & Annual & 0.3 \\
C07 & Winter & 0.8 \\
C08 & Summer & 72.1 \\
C09 & Summer & 0.3 \\
C10 & Annual & 29.7 \\
C11 & Winter & 1.6 \\
C12 & Spring & 0.2 \\
C13 & Spring & 4.9 \\
C14 15 & Summer \\
C16 17 & Spring & 1.4 \\
D01 & Spring & 0.2 \\
D02 & Annual \\
D03 & Annual & 0.4 \\
& Summer & 6.0 \\
& & 1.8 \\
\hline
\end{tabular}

mixed forest in general) is related to $P$. thunbergii, one of the coastal types of conifer in Kong's study (2005), which are located in the southern coastal area and Mt. Gyeryong. Also, HyTAG-C includes Camellia japonica (EB). This is closely related to the latitudinal and altitudinal distribution of subtropical EB trees previously reported by Koo et al. (2001). In their study, C. japonica inhabited a southern coastal area corresponding to an MTC of $-9.0^{\circ} \mathrm{C}$ (MTCI: -63.6), and these native Korean species are the warmthtolerant evergreen broadleaf species at the northern limit of their distribution.

Lastly, intermediate clusters ( $\mathrm{BB}$ and $\mathrm{BC}$ ) were defined by the intersections between spatial extensions of relevant primary clusters. Also, the extension

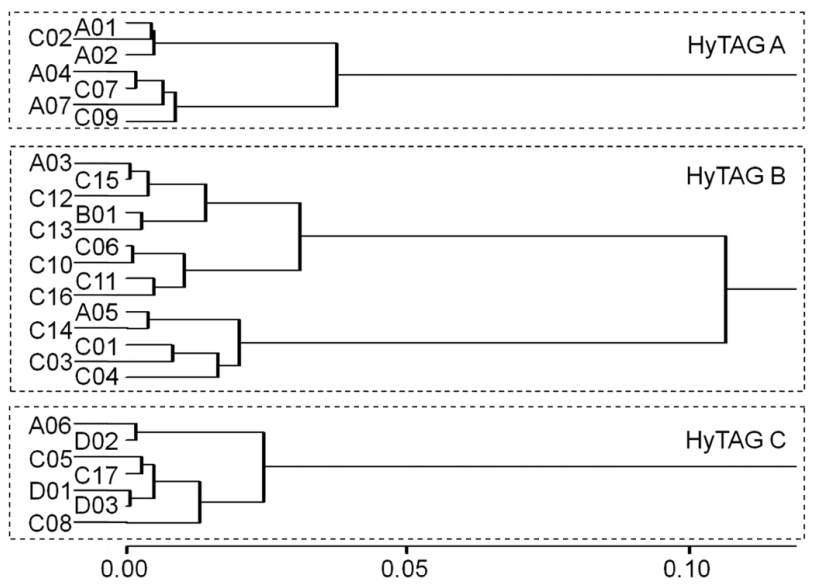

Fig. 8. Hierarchical clustering analysis (HCA) to define hydrological and thermal analogy groups (HyTAGs) 
Table 4. Plant functional types (PFT) and tree species composition along the hydrological and thermal analogues (HyTAGs). EN: evergreen needle-leaved, DN: deciduous needle-leaved, DB: deciduous broad-leaved, EB: evergreen broad-leaved

\begin{tabular}{|c|c|c|c|}
\hline General PFTs & HyTAGs & Species codes & Species \\
\hline Subalpine coniferous forest & HyTAG-N & \multicolumn{2}{|c|}{ Subalpine type not in this study (WI $<75^{\circ} \mathrm{C}$ ) } \\
\hline Cool-temperate mixed forest & HyTAG-A & $\begin{array}{l}\text { A01, A02, A04, A07, } \\
\text { C02, C07, C09 }\end{array}$ & $\begin{array}{l}\text { EN: Abies koreana, Abies nephrolepis, } \\
\text { Pinus koraiensis, Taxus cuspidata } \\
\text { DB: Betula ermanii, Cornus controversa, } \\
\text { Juglans mandshurica }\end{array}$ \\
\hline Cool-temperate deciduous forest & HyTAG-AB & \multicolumn{2}{|l|}{ Both in HyTAG-A and B } \\
\hline Temperate mixed forest & HyTAG-B & $\begin{array}{l}\text { A03, A05, B01, C01, } \\
\text { C03, C04, C06, C10, C11, } \\
\text { C12, C13, C14, C15, C16 }\end{array}$ & $\begin{array}{l}\text { EN: Pinus densiflora, Pinus rigida } \\
\text { DN: Larix kaempferi } \\
\text { DB: Acer mono, Carpinus laxiflora, } \\
\text { Carpinus tschonoskii, Castanea crenata, } \\
\text { Quercus acutissima, Quercus aliena, } \\
\text { Quercus dentata, Quercus mongolica, } \\
\text { Quercus serrata, Quercus variabilis, } \\
\text { Robinia pseudoacacia }\end{array}$ \\
\hline Temperate deciduous forest & HyTAG-BC & \multicolumn{2}{|l|}{ Both in HyTAG-B and C } \\
\hline Warm-temperate mixed forest & HyTAG-C & $\begin{array}{l}\text { A06, C05, C08, C17, } \\
\text { D01, D02, D03 }\end{array}$ & $\begin{array}{l}\text { EN: Pinus thunbergii } \\
\text { DB: Carpinus turczaninovii, Fagus crenata, } \\
\text { Zelkova serrata } \\
\text { EB: Camellia japonica, Castanopsis sieboldii, } \\
\quad \text { Quercus acuta }\end{array}$ \\
\hline Warm-temperate evergreen forest & HyTAG-T & \multicolumn{2}{|c|}{ Warm temperate type not in this study $\left(75^{\circ} \mathrm{C}<\mathrm{WI}<125^{\circ} \mathrm{C}\right)$} \\
\hline Subtropical evergreen forest & HyTAG-S & \multicolumn{2}{|c|}{ Subtropic type not in this study $\left(125^{\circ} \mathrm{C}<\mathrm{WI}\right)$} \\
\hline
\end{tabular}
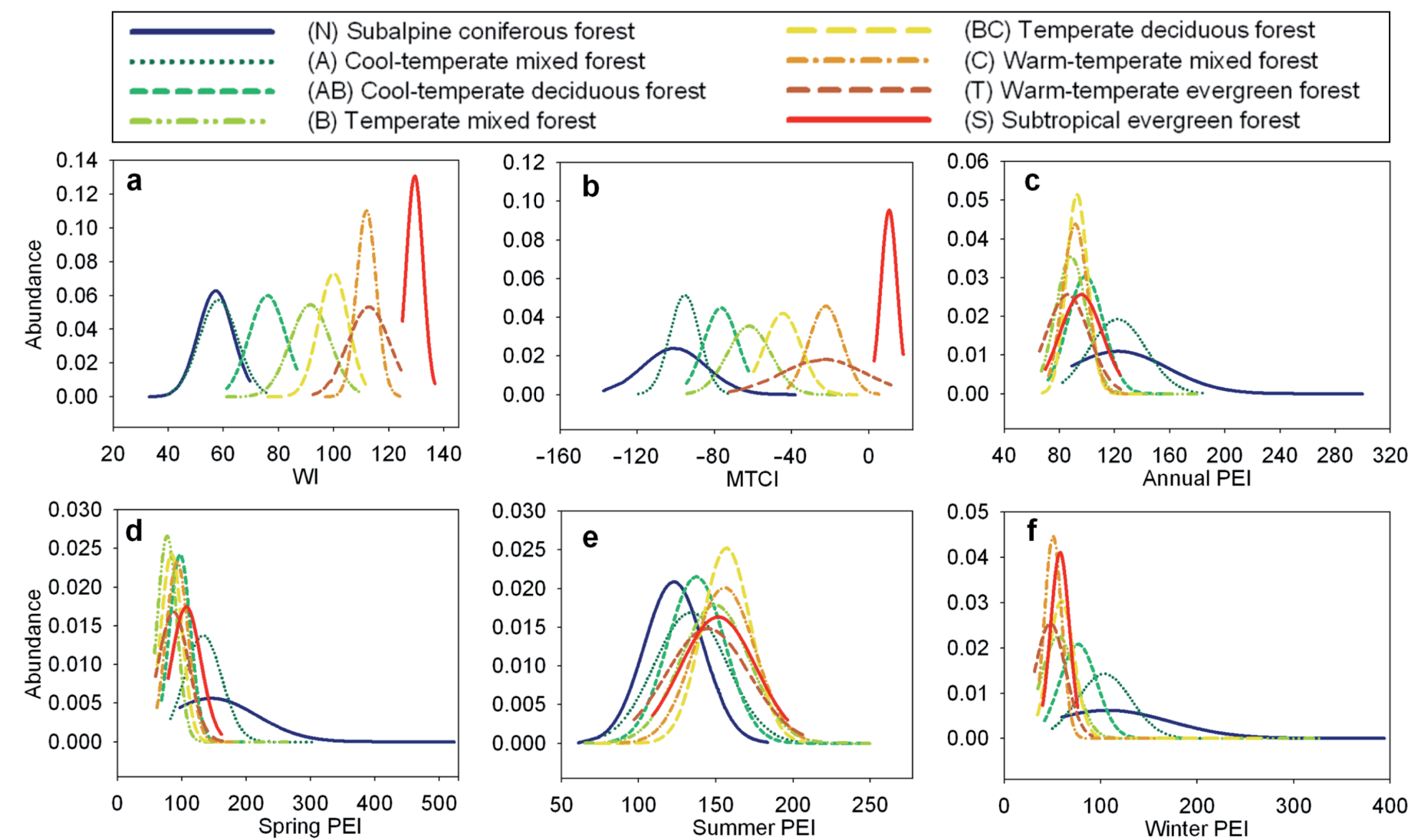

Fig. 9. Abundance and range of climatic limiting factors for hydrological and thermal analogy groups (HyTAGs) (a) Warmth Index (WI); (b) Minimum Temperature of the Coldest Month Index (MTCI); and (c) annual, (d) spring, (e) summer and (f) winter Precipitation-Evaporation Index (PEI) 
Table 5. HyTAG model validation. A: cool-temperate mixed forest; $\mathrm{B}$ : temperate mixed forest ${ }_{;} \mathrm{C}$ : warm-temperate mixed forest. Area identified $\left(\mathrm{km}^{2}\right)-\mathrm{S}_{\text {act }}$ : only in the actual vegeta-

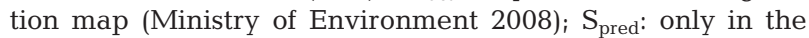
simulated results; $\mathrm{S}_{\mathrm{both}}$ : containing species of interest in both the vegetation map and simulated results. $\mathrm{S}_{\text {union }}=\mathrm{S}_{\mathrm{act}}+\mathrm{S}_{\text {pred }}-$ $\mathrm{S}_{\text {both }}\left(\mathrm{km}^{2}\right)$. CA(\%): classification accuracy; $\operatorname{PrP}(\%)$ : prediction probability

\begin{tabular}{|lcccc|}
\hline & HyTAG-A & HyTAG-B & HyTAG-C & Overall \\
\hline $\mathrm{S}_{\text {act }}$ & 593 & 64977 & 8615 & 74185 \\
$\mathrm{~S}_{\text {pred }}$ & 4255 & 22086 & 5616 & 31957 \\
$\mathrm{~S}_{\text {both }}$ & 299 & 22030 & 3671 & 26000 \\
$\mathrm{~S}_{\text {union }}$ & 4549 & 65033 & 10560 & 80142 \\
$\mathrm{CA}(\%)$ & 6.6 & 33.9 & 34.8 & 32.4 \\
PrP (\%) & 50.4 & 33.9 & 42.6 & 35.0 \\
& & & & \\
\hline
\end{tabular}

not covered by potential distribution of listed major tree species was classified as HyTAG-N (subalpine coniferous forest in general), - $\mathrm{T}$ (warm-temperate evergreen forest in general), and -S (subtropical evergreen forest in general) based on the WI ranges WI < $75^{\circ} \mathrm{C}, 75^{\circ} \mathrm{C}<\mathrm{WI}<125^{\circ} \mathrm{C}$, and $125^{\circ} \mathrm{C}<\mathrm{WI}$, respectively (Table 4). Each HyTAG has relevant ranges of bioclimatic limiting factors (Fig. 9).

The reference distributions for HyTAG validation were the aggregated areas of the single tree species relevant to each HyTAG. CA and PrP were estimated for overall distributions of HyTAG-A, -B, and -C. The overall CA was $32.4 \%$ (PrP: $35.0 \%$ ), because the habitats of some tree species were relatively smaller than the area predicted by the HyTAG (Table 5).

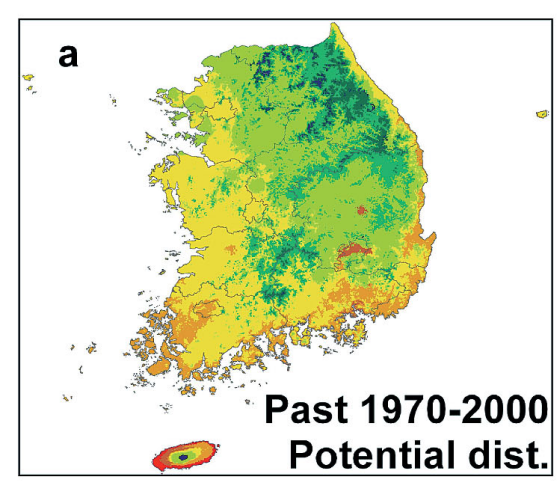

\begin{tabular}{|ll|}
\hline$\square$ (N) Subalpine coniferous & (BC) Temperate deciduous \\
(A) Cool-temperate mixed & (C) Warm-temperate mixed \\
& (AB) Cool-temperate deciduous \\
(T) Warm-temperate evergreen \\
$\square$ (B) Temperate mixed & (S) Subtropical evergreen \\
\hline
\end{tabular}

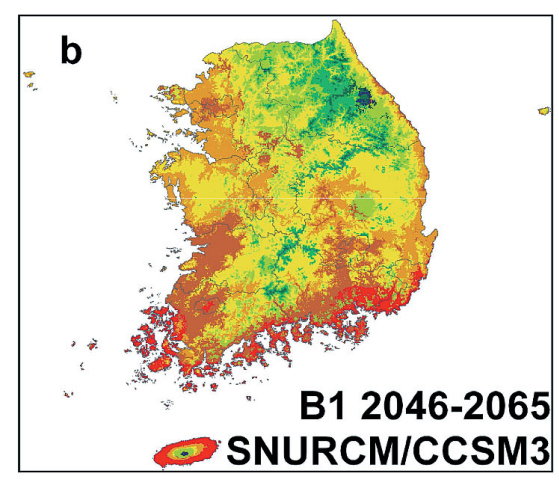

$0 \quad 125 \quad 250 \quad 500 \mathrm{~km}$
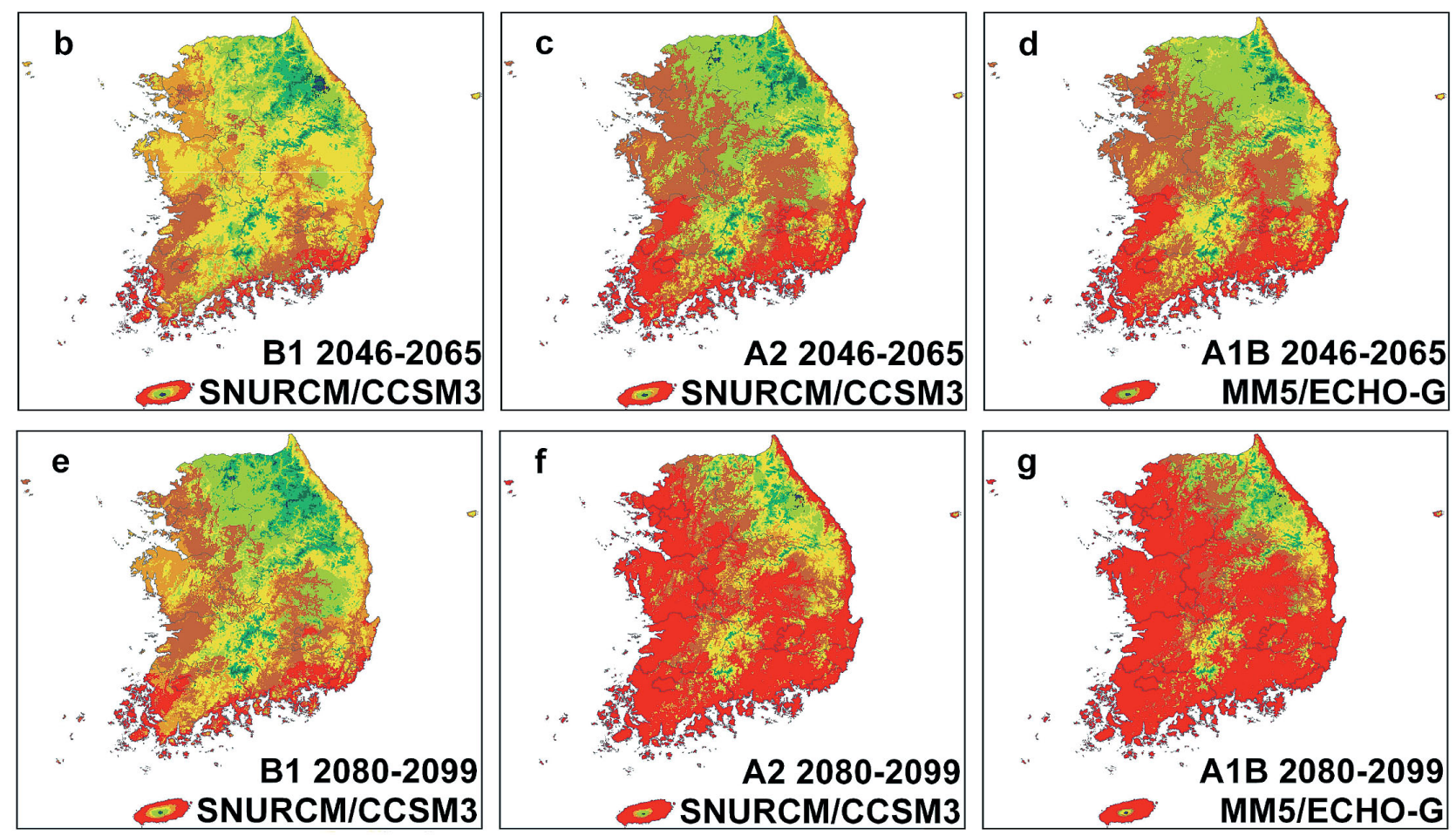

Fig. 10. Changes in potential forest distribution under IPCC scenarios B1, A2, and A1B and periods (year range): (a) past, (b-d) near future, and (e-g) far future, as depicted by the hydrological and thermal analogy groups (HyTAGs) 

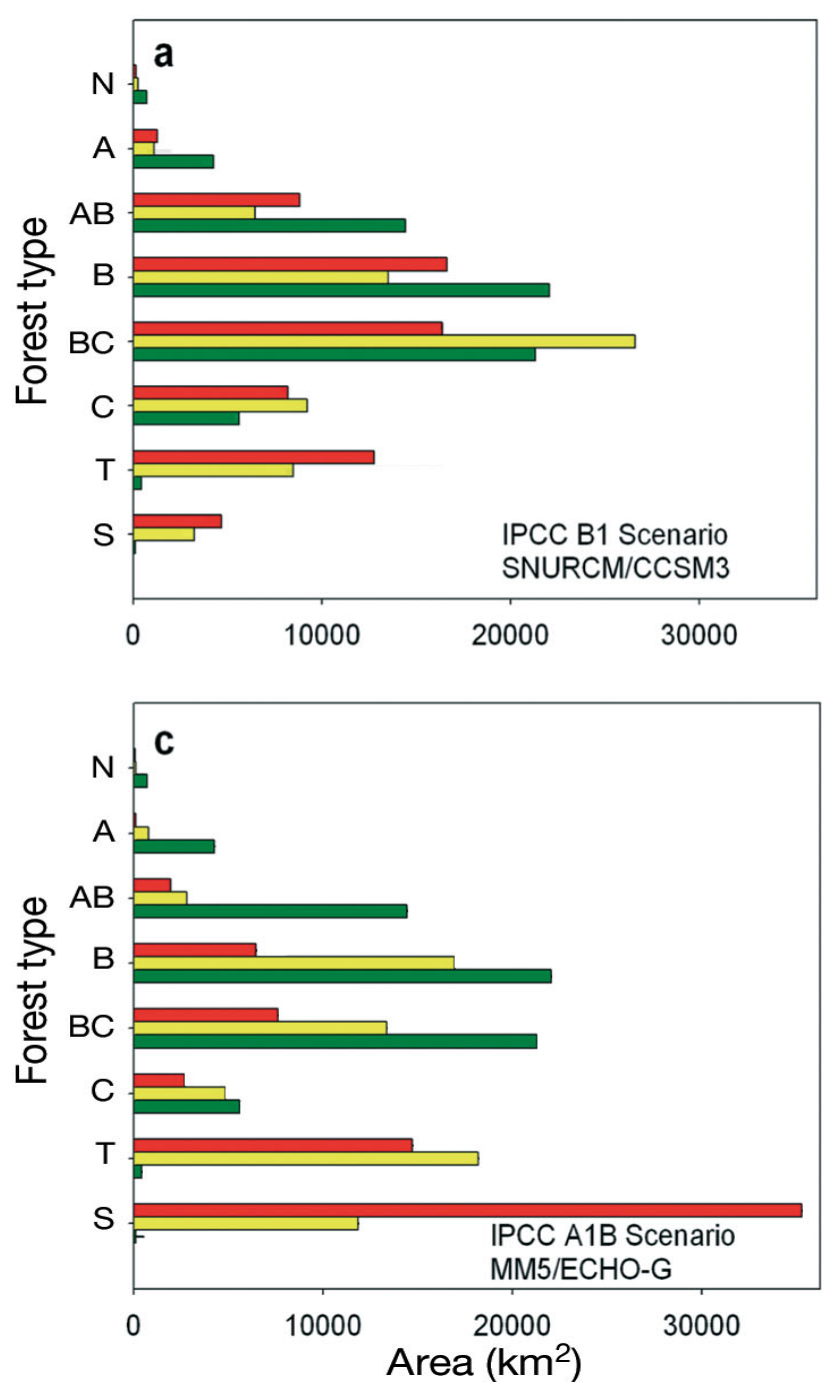

\subsection{Potential forest vegetation distribution}

We defined 8 HyTAGs for Korea in terms of the PFT, whereas other models suggested 4 or 5 types to explain the vegetation distribution of Korea. Therefore, it can more specifically explain the effects of climate change on a regional scale than previous global or continental scale vegetation models. The results presented in Figs. 10 \& 11 show that the distribution of HyTAGs will probably change as the subalpine type (HyTAG-N) and cool-temperate mixed forest (HyTAG-A) shrink in the future at different rates, depending on IPCC climate change scenarios. The aggregated distribution of HyTAG-N and -A was changed from $5.0 \%\left(\sim 5036 \mathrm{~km}^{2}\right)$ in the past, to $1.4 \%$ in near and far future under IPCC B1 scenario. On the other hand, the aggregated distribution of HyTAG-N and -A decreased by a different rate in IPCC A2 and A1B scenarios: 1.7 to $0.2 \%$ (near to far
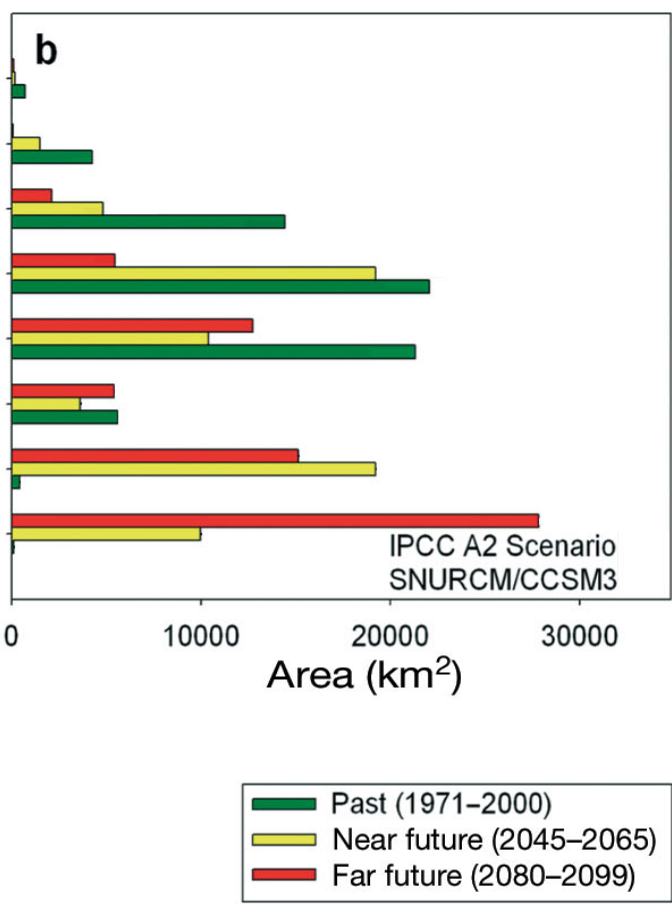

Fig. 11. Changes in total area of potential forest distribution under IPCC scenarios (a) B1, (b) A2, and (c) A1B (N) Subalpine coniferous forest, (A) Cool-temperate mixed forest, (AB) Cool-temperate deciduous forest, (B) Temperate mixed forest, (BC) Temperate deciduous forest, (C) Warm-temperate mixed forest, (T) Warm-temperate evergreen forest, (S) Subtropical evergreen forest. Nonforest pixels were excluded

future) and 0.9 to $0.2 \%$ (near to far future), respectively. When we excluded non-forest pixels), the aggregated area of HyTAG-N and -A occupied 7.2\% $\left(\sim 4977 \mathrm{~km}^{2}\right)$ of the total forest area in the past. The aggregated natural HyTAG-N and -A area will decrease to $2.0 \%$ (near future) and $2.1 \%$ (far future) under IPCC B1 scenario.

Change will also occur with the expansion of warmtemperate evergreen forest (HyTAG-T), subtropic type (HyTAG-S), and warm-temperate mixed forest (HyTAG-C), which is mainly composed of EB trees such as Camellia japonica. The aggregated distribution of HyTAG-C, -T and -S increased from $8.9 \%$ (past) to 30.4 and $37.2 \%$ in near and far future, respectively, under the B1 scenario, 47.6 and $70.2 \%$ under the A2 scenario, and 50.6 and $76.5 \%$ under the A1B scenario. As shown in Fig. 10a, based on the past climatic conditions (1971-2000), the HyTAG-A and $-\mathrm{AB}$ covered a high mountain region. However, 
as shown in Fig. 10b-g, the aggregated area of HyTAG-A and -AB will decrease in the near future (2046-2065) and fade away in the far future (20802099). In the past (1971-2000), HyTAG-BC and -C were well distributed in the southern inland and eastern coastal areas. As a result of climate change, HyTAG-BC and -C are gradually losing their past habitats and are predicted to shrink to the eastern mountainous region in the far future (2080-2099). These results from the static bioclimatic classification demonstrated that the past and current forest distribution will become exposed to an unsuitable climatic condition for their habitat in the near and far future.

Previous studies applied a grouping and zoning process to show Korean ecosystem distributions. However, such approaches are insufficient to generate a detailed distribution of forest vegetation. For example, the thresholds of Yim $(1977 a, b)$ classified the Korean forest ecosystem into only 5 major groups: warm-temperate, temperate zone-southern part, temperate zone-middle part, temperate zonenorthern part, and arctic zone. The simulation of DGVMs (CEVSA and MC1 model) had only 4 major groups explaining the potential vegetation distribution in Korea (Lee et al. 2007a, Choi et al. 2010a). Even though the TAG model employed 22 PFTs, as the hydrological factor was not considered as a controlling climatic variable in the forest cover distribution, it could not explain the topographical characteristics in detail (Choi et al. 2010b).

\section{CONCLUSIONS}

This study's main objective was to predict the potential changes of forest distribution within Korea in the past (1971-2000), near future (2045-2065), and far future (2080-2099). In particular, we examined the distributional changes under the 3 IPCC climate change scenarios B1, A1B, and A2. Compared to previous investigations, our research generated more detailed patterns of potential forest distribution changes in Korea. Bioclimatic limiting factors such as Thornthwaite's PEI, Kira's WI, and Neilson's MTCI were applied to find the optimal hydrological and thermal habitat ranges of principal tree species. The most important finding was the identification of new plant functional types (8 HyTAGs) to explain the geographical characteristics and ecological features of Korea. The CA value of the HyTAG model simulation was $32.4 \%$ (PrP: $35.0 \%$ ), predictive for overall distributions of cool-temperate (HyTAG-A), temperate (HyTAG-B), and warm-temperate (HyTAG-C) mixed forests. Fur- thermore, the HyTAGs predicted that climate change will enhance the shrinking of areas that are mainly occupied by the cool-temperate mixed forests (HyTAG-N, -A, and -AB). Conversely, climate change would result in the expansion of habitats occupied by the warm-temperate mixed forests (HyTAG-S, -C, and $-\mathrm{BC}$ ). Rates of change in vegetation cover differed among the 3 IPCC climate change scenarios.

The HyTAG model however, has a number of limitations. It requires consideration of soil conditions and human-related impacts in order to increase reliability and accuracy. Satellite-based information and field surveys may help to make the model more accurate in considering the present factors of environmental features and human activities that are affecting forest ecosystems. In addition, this study only predicted distributional changes of forest and was not able to assess carbon flux. This may be solved by adapting algorithms of tree growth and forest physiological models that are capable of estimating carbon flux in forest ecosystems.

Acknowledgements. This work was supported by the Korea Forest Research Institute research project 'Impact Assessment of Climate Change on Forest Ecosystem and Development of Adaptation Strategies' (Grant No.FE 0100-2009-01) and by research grants from the Korea Science and Engineering Foundation (Grant No. A307-K0001) and the National Research Foundation (NRF-2010-013-F00004).

\section{LITERATURE CITED}

Arris LL, Eagleson PS (1989) Evidence of a physiological basis for the boreal-deciduous forest ecotone in North America. Vegetatio 82:55-58

Bachelet D, Lenihan JM, Daly C, Neilson RP, Ojima DS, Parton WJ (2001) MC1: a dynamic vegetation model for estimating the distribution of vegetation and associated carbon, nutrients, and water. General Tech Rep PNWGTR-508 version 1.0, USDA, Portland, OR

Box EO (1996) Plant functional types and climate at the global scale. J Veg Sci 7:309-320

Cao MK, Woodward FI (1998) Dynamic responses of terrestrial ecosystem carbon cycling to global climate change. Nature 393:249-252

Cha DH, Lee DK (2009) Reduction of systematic errors in regional climate simulations of the summer monsoon over East Asia and the western North Pacific by applying the spectral nudging technique. J Geophys Res 114: D14108. doi:10.1029/2008JD011176

Cha YM, Lee HS, Moon JY, Kwon WT, Boo KE (2007) Future climate projection over East Asia using ECHO-G/S. Atmosphere (Seoul) 17:55-68 (in Korean)

> Chapin FS, Bret-Harte MS, Hobbie SE, Zhong H (1996) Plant functional types as predictors of transient responses of arctic vegetation to global change. J Veg Sci $7: 347-358$

Cho HL, Jeong JC (2006) Application of spatial interpolation to rainfall data. J GIS Assoc Korea 14:29-41 (in Korean) 
Choi S, Lee WK, Kwak HB, Kim SR and others (2010a) Vulnerability assessment of forest ecosystem to climate change in Korea using MC1 model. Jpn J For Plan 16: 149-161

Choi S, Lee WK, Son Y, Yoo S, Lim JH (2010b) Changes in the distribution of South Korean forest vegetation simulated using thermal gradient indices. Sci China Life Sci 53:784-797

Fang JY, Yoda K (1989) Climate and vegetation in China (II). Distribution of main vegetation types and thermal climate. Ecol Res 4:71-83

Fang JY, Yoda K (1990a) Climate and vegetation in China (III). Distribution of main vegetation types and thermal climate. Ecol Res 5:9-23

Fang JY, Yoda K (1990b) Climate and vegetation in China (IV). Distribution of main vegetation types and thermal climate. Ecol Res 5:291-302

Gavilan RG (2005) The use of climatic parameters and indices in vegetation distribution: a case study in the Spanish Sistema Central. Int J Biometeorol 50:111-120

Horikawa M, Tsuyama I, Matsui T, Kominami Y, Tanakaet N (2009) Assessing the potential impacts of climate change on the alpine habitat suitability of Japanese stone pine (Pinus pumila). Landscape Ecol 24:115-128

IPCC (Intergovernmental Panel on Climate Change) (2000) Special report on emissions scenarios. Cambridge University Press, Cambridge

> Iverson LR, Prasad AM (1998) Predicting abundance of 80 tree species following climate change in the eastern United States. Ecol Monogr 68:465-485

KEI (Korea Environment Institute) (2008) Recommendations for improvement to establish the better map of actual vegetation. In: Jeong WS (ed) Environmental forum 12(4):1-8 (in Korean)

KFS (Korea Forest Service) (2009) Statistical Yearbook of Forestry 2008. Korea Forest Service, Seoul, p 30-32 (in Korean)

Kim JU, Lee DK (2006) A study on the vulnerability assessment of forest vegetation using regional climate model. J Korean Soc Environ Restoration Revegetation Technol 9:32-40

Kim SN, Lee WK, Son Y, Cho Y, Lee MS (2009) Applicability of climate change impact assessment models to Korean forest. J Korean For Soc 98:33-48

Kira T (1945) A new classification of climate in eastern Asia as the basis for agricultural geography. Horticultural Institute, Kyoto University, Kyoto (in Japanese)

Kong WS (2004) Species composition and distribution of native Korean conifers. J Korean Geogr Soc 39:528-543 (in Korean)

Kong WS (2005) Selection of vulnerable indicator plants by global warming. Asia-Pac J Atmos Sci 41(2-1):263-273 (in Korean)

Koo KA, Kong WS, Kim CK (2001) Distribution of evergreen broad-leaved plants and climatic factors. J Korean Geogr Soc 36:247-257 (in Korean)

Laurent JM, Bar-Hen A, Francois L, Ghislain M, Cheddadi R (2004) Refining vegetation simulation models: from plant functional types to bioclimatic affinity groups of plants. J Veg Sci 15:739-746

Lee CS, Kim JH, Yi H, You YH (2004) Seedling establishment and regeneration of Korean red pine (Pinus densiflora $\mathrm{S}$. et Z.) forests in Korea in relation to soil moisture. For Ecol Manage 199:423-432

Lee MA, Lee WK, Son Y, Cho Y and others (2007a) Sensitiv- ity and adaptability of vegetation and soil carbon storage to climate change with CEVSA model in Korea. In: Son Y, Muraoka H, Fang JY (eds) Proc A3 Foresight Program, KOSEF, Seoul, p 24

Lee MA, Lee WK, Song CC, Lee JH, Choi HA, Kim TM (2007b) Spatio-temporal change prediction and variability of temperature and precipitation. J GIS Assoc Korea 15:1-12 (in Korean)

Lenihan JM, Drapek R, Bachelet D, Neilson R (2003) Climate change effects of vegetation distribution, carbon, and fire in California. Ecol Appl 13:1667-1681

Lenihan JM, Bachelet D, Neilson RP, Drapek R (2008) Response of vegetation distribution, ecosystem productivity, and fire to climate change scenarios for California. Clim Change 87:S215-S230

Lull HW, Ellison L (1950) Precipitation in relation to altitude in central Utah. Ecology 31:479-484

Mather JR, Yoshioka GA (1968) The role of climate in the distribution of vegetation. Ann Assoc Am Geogr 58:29-41

Matsui T, Yagihashi T, Nakaya T, Tanaka N, Taoda H (2004a) Climate controls on distribution of Fagus crenata forests in Japan. J Veg Sci 15:57-66

Matsui T, Yagihashi T, Nakaya T, Taoda H, Yoshinaga S, Daimaru H, Tanaka N (2004b) Probability distributions, vulnerability and sensitivity in Fagus crenata forests following predicted climate changes in Japan. J Veg Sci 15:605-614

McCabe GJ, Wolock DM (1992) Effects of climate change and climatic variability on the Thornthwaite moisture index in the Delaware River basin. Clim Change 20: 143-153

Min SK, Legutke S, Hense H, Cubasch U, Kwon WT, Oh JH, Schles U (2006) East Asian climate change in the 21st century as simulated by the coupled climate model ECHO-G under IPCC SRES scenarios. J Meteorol Soc Jpn 82:1187-1211

Ministry of Environment (2008) The map of actual vegetation. Ministry of Environment, Seoul (in Korean)

Neilson RP (1993) Transient ecotone response to climate change: some conceptual and modeling approaches. Ecol Appl 3:385-395

Neilson RP (1995) A model for predicting continental-scale vegetation distribution and water balance. Ecol Appl 5: 362-385

Neilson RP, Marks D (1994) A global perspective of regional vegetation and hydrological sensitivities from climate change. J Veg Sci 5:715-730

NGII (National Geographic Information Institute) (2007) The National Atlas of Korea 2007, available at: http://atlas. ngii.go.kr/english/explanation/natural_1_1.jsp (accessed 01 Dec 2007)

Ohsawa M (1993) Latitudinal pattern of mountain vegetation zonation in southern and eastern Asia. J Veg Sci 4: $13-18$

Osborne CP, Mitchell PL, Sheehy JE, Woodward FI (2000) Modelling the recent historical impacts of atmospheric $\mathrm{CO}_{2}$ and climate change on Mediterranean vegetation. Glob Change Biol 6:445-458

Park NW, Jang DH (2008) Mapping of temperature and rainfall using DEM and multivariate kriging. J Korean Geogr Soc 43:1002-1015 (in Korean)

Park WK, Yadav RR (1998) A dendroclimatic analysis of Pinus densiflora from Mt. Chiri in southern Korea. Ann Sci 55:451-459

Prentice IC, Cramer W, Harrison SP, Leemans R, Monserud 
RA, Solomon AM (1992) A global biome model based on plant physiology and dominance, soil properties and climate. J Biogeogr 19:117-134

Riera JL, Magnuson JJ, Castle JR, Mackenzie MD (1998) Analysis of large-scale spatial heterogeneity in vegetation indices among North American landscapes. Ecosystems 1:268-282

Sakai A (1978) Freezing tolerance of evergreen and deciduous broad-leaved trees in Japan with reference to tree regions. Low Temp Sci Ser B Biol Sci 36:1-19

Sakai A, Paton DM, Wardle P (1979) Freezing resistance of temperate and sub-arctic conifers native to the southern hemisphere. Low Temp Sci Ser B Biol Sci 37:107-111

SAS (2009) SAS 9.2 Help and documentation. SAS Institute, Cary, NC

Setzer J (1946) A new formula for precipitation effectiveness. Geogr Rev 36:247-263

Smith CD (2007) Chapter 10: The relationship between monthly precipitation and elevation in the Alberta foothills during the Foothills Orographic Precipitation Experiment. In: Woo MK (ed) Cold region atmospheric and hydrologic studies. Springer, Berlin, p 167-185

Stephenson NL (1990) Climatic control of vegetation distribution: the role of the water balance. Am Nat 135: 649-670

Stephenson NL (1998) Actual evapotranspiration and deficit: biologically meaningful correlates of vegetation distribution across spatial scales. J Biogeogr 25:855-870

Strimbeck GR, Kjellsen TD, Schaberg PG, Murakami PF (2007) Cold in the common garden: comparative lowtemperature tolerance of boreal and temperate conifer foliage. Trees (Berl) 21:557-567

Takyu M, Kubota Y, Aiba S, Seino T, Nishimura T (2005)

Editorial responsibility: Tim Sparks, Cambridge, UK
Patterns of changes in species diversity, structure and dynamics of forest ecosystems along latitudinal gradients in East Asia. Ecol Res 20:287-296

Thornthwaite CW (1948) An approach toward a rational classification of climate. Geogr Rev 38:55-94

Usman S, Sigh SP, Rawat YS (1999) Fine root productivity and turnover in two evergreen Central Himalayan forests. Ann Bot (Lond) 84:87-94

Watanabe T, Yokozawa M, Emori S, Takata K, Sumida A, Hara T (2004) Developing a multilayered integrated numerical model of surface physics-growing plants interaction (MINoSGI). Glob Change Biol 10:963-982

Woodward FI (1987) Climate and plant distribution. Cambridge University Press, Cambridge, p 117-160

Woodward FI, Lomas MR, Kelly CK (2004) Global climate and the distribution of plant biomes. Philos Trans R Soc Lond B Biol Sci 359:1465-1476

Yang KC, Shim JK (2007) Distribution of major plant communities based on the climatic conditions and topographic features in South Korea. Korean J Environ Biol 25:168-177 (in Korean)

Yim YJ (1977a) Distribution of forest vegetation and climate in the Korean Peninsula. III. Distribution of tree species along the thermal gradient. Jap J Ecol 27:177-189

Yim YJ (1977b) Distribution of forest vegetation and climate in the Korean Peninsula. IV. Distribution of tree species along the thermal gradient. Jap J Ecol 27:269-278

$>\mathrm{Yu}$ L, Cao MK, Li K (2006) Climate-induced changes in the vegetation pattern of China in the 21 st century. Ecol Res 21:912-919

Yun JI, Choi JY, Ahn JH (2001) Seasonal trend of elevation effect on daily air temperature in Korea. Korean J Agric For Meteorol 3:96-104 (in Korean)

Submitted: September 8, 2010; Accepted: June 29, 2011

Proofs received from author(s): November 7, 2011 